\title{
A Chinese Approach to Urban Heritage Conservation and Inheritance: Focus on the Contemporary Changes of Shanghai's Historic Spaces*
}

\author{
Qing Chang \\ College of Architecture and Urban Planning, Tongji University, Shanghai, China \\ Email: changqingtj@vip.sina.com
}

\begin{abstract}
By taking the Laochengxiang area, the lilong houses, the Bund and the industrial heritage as typical examples, this paper discusses the problems related to the conservation and regeneration of built heritage in Shanghai against the backdrop of large-scale urban development and the transformation of historic spaces in the city since the 1990s. It analyses the contradiction between development and heritage conservation in the process of urban redevelopment, and proposes a resolution to such problems. Furthermore, the paper has a reflection and analysis on the specific historical context of Shanghai as a metropolis and its changes from the past to the present.
\end{abstract}

KEYWORDS historic space, historical urban context, changes, conservation, inheritance

Received August 12, 2017; accepted September 6, 2017.

\section{The Status Quo of Shanghai and Its Architecture}

\section{City Scale}

The study of the architectural transformations in the course of the renovation of the old urban areas of Shanghai requires some basic understandings of the city, the first of which is its architectural feature determined by its size and density. The total area of Shanghai is $6,833 \mathrm{~km}^{2}$ and its current urban area which means the area within the outer ring road is $663.5 \mathrm{~km}^{2}$, being 10 times and 8 times bigger respectively than the figures when the People's Republic of China was founded in 1949. The current long-term resident population exceeds 24 million, of which more than 14 million are registered permanent residents, and nearly 10 million are migrant inhabitants. At the start of the People's Republic of China, the urban area of Shanghai was only $82.4 \mathrm{~km}^{2}$ while the entire city area was up to $630 \mathrm{~km}^{2}$. The permanent residents at that time had already surpassed 4 million, among which 3 million were packed within the urban area. Today, the urban centre of Shanghai encircled by the inner ring

* This paper is a substantial rewrite of 'Shanghai Buildings Re-modeled in Old District and the Metropolitan Historical Discourse Context', (Chang 2009a) with new sections added and major updates in texts and figures. road includes most of the old urban area of Shanghai, and the average population density is near that at the beginning of the People's Republic of China (SUPAB 2007, 13-14, 47, 50). Though the population density within the inner ring road has stayed high, the expansion rate of the urban space has successfully exceeded that of the population increase for the past 20 years. Due to the continuous strong urbanisation and urban redevelopment, the per capita living space of the entire city of 2015 has increased 6 times compared to that of the 1950s, reaching $24.13 \mathrm{~m}^{2}$; the per capita green space has reached over $13 \mathrm{~m}^{2}$; and the per capita public park area is $7.82 \mathrm{~m}^{2}$. The change brought about by such high-intensity urban redevelopment in such a short period of time is a great achievement that has been universally recognised. At the meantime, however, there is also an inevitable price for this. For instance, the overall environmental quality has not improved proportionally, the 'community barriers' brought about by the stratification of urban spaces and social classes have aggravated, and the contradiction between the conservation and redevelopment of historic spaces has emerged.

The political background of this great urban transformation is the gradual change to the state control of land 
development and construction rights under the planned economy. In May 1990, the adoption of the Interim Regulations of the People's Republic of China Concerning the Assignment and Transfer of the Right to the Use of the State-owned Land in the Urban Areas is a landmark turning point. Shanghai truly took flight from this point on. Following Mr Deng Xiaoping's speech encouraging for the development of the Pudong District during his visit to Shanghai in 1992, the face of Shanghai's urban architecture underwent tremendous transformation. The spatial presentation of this transformation is the rapid growth of colossal high-rise structures. The pressure of a bigger population, the demand for additional spaces, the consideration of real estate values, and the effects of intensification, have caused the sustained increase of the height and quantity of Shanghai's highrises, and effectively created a dense forest of steel, concrete and glass.

\section{Building Scale}

In 1949, there were no more than 100 high-rise buildings in all of Shanghai. At that time, the 24-storey, 83.8-metrehigh Park Hotel, which was built in 1934 on West Nanjing Road, was not only the tallest building in Shanghai but also in the Far East. Remarkably, this building had remained the tallest in Shanghai for 48 years until 1982, when it was surpassed by the 30-storey, 91.5-metre-high Shanghai Hotel at the intersection of Wulumuqi Road and Huashan Road. Currently in Shanghai, buildings over $24 \mathrm{~m}$ high have exceeded 10,000 in number, which is more than 100 times the amount at the beginning of the People's Republic. Super high-rises constitute over $4 \%$ of these buildings, the majority of which have been constructed since the 1990s. The 121-storey, 632-metrehigh Shanghai Tower has surpassed the 492-metre-high Shanghai World Financial Centre to become the new symbol of super high-rises in Shanghai. An equally striking example can be found in two cases of residential high rise. One is the COSCO Two Bay City, a high-densityskyscraper residential block at Zhongtan Road on the northern bank of the Suzhou Creek, covering an area of $1,600,000 \mathrm{~m}^{2}$, the maximum floor area ratio of which reaches 3.4. The other is the Building Two of the Shimao Riviera Garden on the shore of the Huangpu River with a height close to $192 \mathrm{~m}$. Looking at the distribution of the high-rise aggregations other than the Bund and the $1.7-\mathrm{km}^{2}$ Lujiazui Central Business District in Pudong New District (which gathers super high-rises and highdensity within a planned construction area reaching
4,000,000 $\mathrm{m}^{2}$ ), there are at least six large Central Business Districts in the central urban area of Shanghai characterised by the tendency to incorporate mega-structures and high-rises, such as Middle Huaihai Road, Xujiahui, People's Square, Hongqiao, West Nanjing Road, and Jiangwan Wujiaochang, all of which are similar to the 'downtown' areas of large Western cities in terms of highrise density. It is no surprise that Shanghai is also known to the world as an 'exploded' Manhattan.

\section{The Meaning of Congestion}

According to the anthropological concept of proxemics, the density and pattern of urban architecture is a spatial portrayal of the relationship between population density and social hierarchical stratifications. When the density reaches a certain threshold, it will result in congestion. Although Le Corbusier's Ville Radieuse had strong utopian overtones, the large number of business districts and high-rise commercial and residential areas actually recall the concepts from Le Corbusier's city. Rem Koolhaas used Manhattan as an example to demonstrate the ambiguous paradigm of the relationship between the reality of hyper-density and the construct of 'the culture of congestion' (Koolhaas 1978). This also illustrated in part that large metropolitan centres inevitably use extremely dense high-rises in super-structured spaces to accommodate the congested reality brought about by the high-density, life complexity, and cultural diversity of the population. The meaning of 'congestion' here should not be taken simply in a negative sense, but also reflects the vitality and potential for growth in a metropolis. The problem is how to effectively control the high-rises and high density to mitigate the environmental and social disadvantages associated with high-rises. More than 10 years ago, Shanghai opted for establishing a limit of 4 in the floor area ratio of commercial areas and of 2.5 for residential areas, which to some extent prevented the radical growth in height and density of the city centre. However, in face of the rapid urban expansion of contemporary Shanghai, those who care about the rich urban cultural features of the city are questioning themselves: what happened to the remains of the glorious old Modern Shanghai? What is its fate in the renewal of the old city? Will the historic space of the metropolitan area be marginalised and fragmented in the enormous expansion of the city? These questions can only be answered by examining the pulse of the urban redevelopment of the old city of Shanghai. 


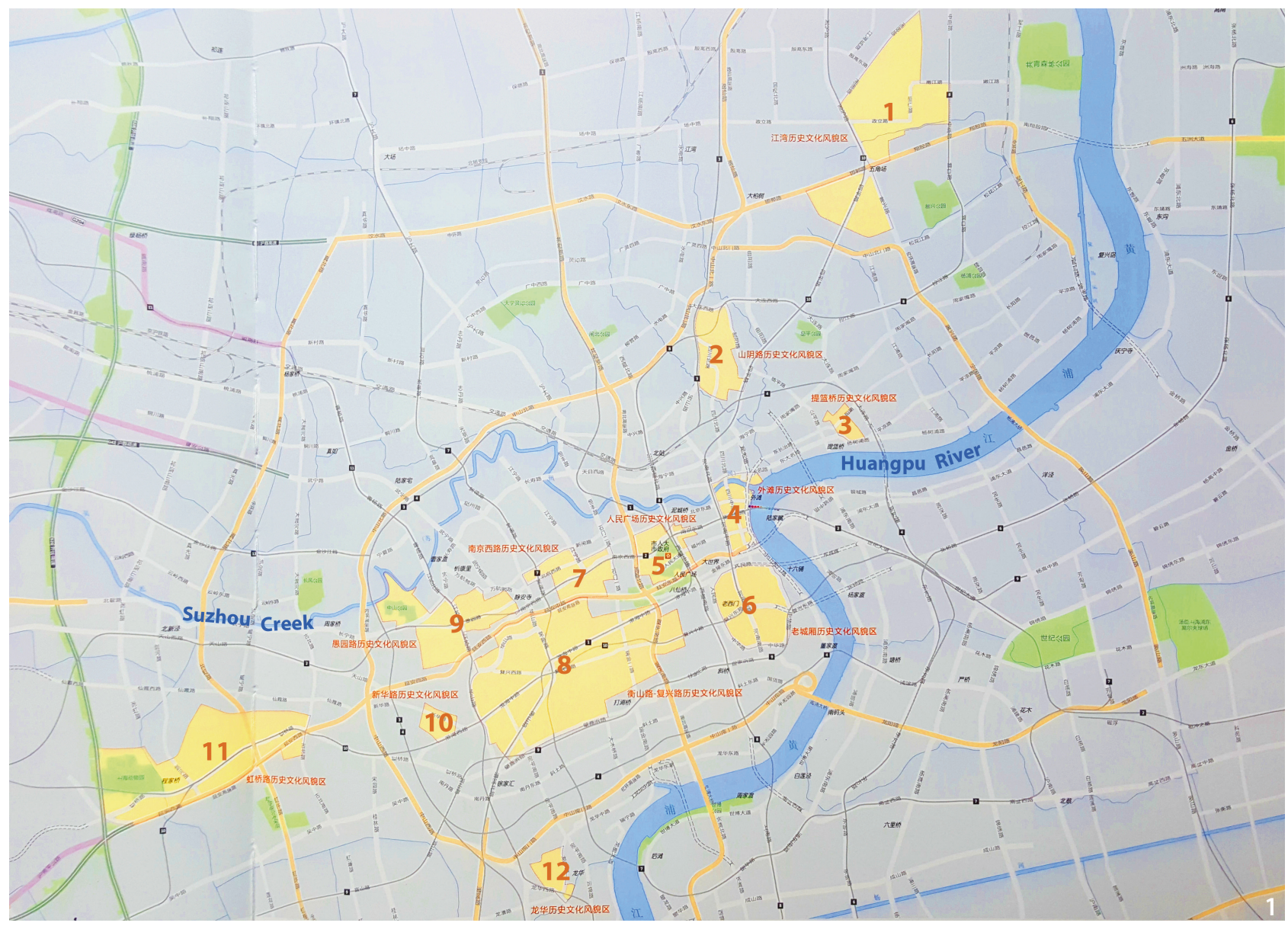

Figure 1 Location of the 12 Historic Areas in the city centre of Shanghai (Source: Shanghai Urban Construction Archive 2014).

1. Jiangwan Historic Area

2. Shanyin Road Historic Area

3. Tilanqiao Historic Area

4. The Bund Historic Area

5. The People's Square Historic Area

6. Laochengxiang Historic Area

\section{The Contradiction between the Conservation and the Redevelopment of Shanghai's Historic Space}

\section{Conserving the Built Heritage}

As mega-structures and high-rises become a dominating feature of Shanghai's urban centre, together with the rapid growth of basic infrastructure such as viaducts and rail transit, Shanghai has already established a new metropolitan image. However, the widely recognised image and identity of Shanghai for over a century have always been based on the city's historic streets and architecture which were laid out in the late $19^{\text {th }}$ century and early $20^{\text {th }}$ century in the former International Settlements and French Concession, and the Laochengxiang area which corresponds to the old walled city and its outer commercial area by the Huangpu River. This constitutes an essential part of
7. West Nanjing Road Historic Area

8. Hengshan Road-Fuxing Road Historic Area

9. Yuyuan Road Historic Area

10. Xinhua Road Historic Area

11. Hongqiao Road Historic Area

12. Longhua Historic Area
Shanghai's charm and diversity (Zheng 2002).

Since the designation of the 'First Batch of Excellent Historic Buildings' in 1989, and especially since the promulgation of the Regulations of Shanghai Municipality on the Protection of Areas with Historical Cultural Features and the Excellent Historical Buildings in 2002, Shanghai has planned and protected around one third of the $82 \mathrm{~km}^{2}$ old urban centre which was formed in the period of the Republic of China (1912-1949), including 12 Historic Areas (lishi wenhua fengmao qu) totalling around $27 \mathrm{~km}^{2}$ in the city centre and 32 such areas totalling around $14 \mathrm{~km}^{2}$ in rural areas, as well as 1,058 Excellent Historic Buildings (youxiu lishi jianzhu). Besides, the city has also identified 119 Historic Quarters (lishi fengmao jiefang) and 167 Historic Conservation Streets/Lanes (fengmao baohu daolu/jiexiang) (Figure 1). While considerable efforts have been made to conserve these heritages, the conflicts between conservation and 
urban redevelopment have become sharper.

As a matter of fact, most historic buildings have been functioning as of modern residential and public facilities. So large-scale 'conservation' is unfortunately a noble but luxurious term. The tremendous economic and social investment for the conservation efforts requires the involvement of all stakeholders. Since it is an indispensable part of the ever-evolving community and social life of the neighbourhood, it needs all the related participation from the users, the investors, the administrators, the scholars and the experts, and the general public. As a result, conservation and rehabilitation become a social project as it relates with political, economic and cultural strategies and their evolvement. The gains and losses in the conservation and regeneration of historic buildings during the urban transformation of Shanghai in the last 30 years have everything to do with the timing and methods used for the renovation of the entire neighbourhoods. Especially since most of these historic buildings are residential buildings or areas (jiuli or old-style lilong houses). First, let's take a look at the redevelopment of jiuli, and then examine the specific conservation and regeneration work of the related historic heritage.

\section{Lilong Shikumen Houses}

The congestion of the old Shanghai is expressed in architectural terms as a combination of high density and lowrises. When the People's Republic of China was founded in 1949, residential buildings comprised about half of the total $46,790,000 \mathrm{~m}^{2}$ built areas in Shanghai, within which a large proportion were lilong shikumen houses (literally means stone gate frame lane houses). Through the large-scale renewal of jiuli since the beginning of the 1990s, Shanghai has completed old-district renewal projects for 830,000 households, totalling $20,760,000 \mathrm{~m}^{2}$, and has gradually undertaken the rehabilitation of additional 400,000 households, or about 564 land parcels totalling $8,740,000 \mathrm{~m}^{2}$ of poor-condition houses. During this process, the methods applied to the conservation and rehabilitation of the lilong houses deserve special attention, which can be categorised into four types.

The first type is the Xintiandi model. Promoted by Hong Kong's Shui On Land Limited., Xintiandi was designed in the second half of the 1990s by the American architect Benjamin Wood, who is well-versed in the regeneration of historic architecture. Around 30,000 $\mathrm{m}^{2}$ of lilong shikumen houses near the site of the First National Congress of the Communist Party of China on South Huangpi Road were redeveloped into an area of restaurants, shopping and entertainment, which could be seen as a Shanghai version of Hong Kong's Lan Kwai Fong. The lenient development compensation policies at the time enabled the developer to acquire the rights to develop the 52 ha Taiping Bridge area (now called Lakeville). It is an excellent contemporary example of commercial redevelopment through the gentrification of old lilong, and is seen as a model for lilong shikumen conservation. It incorporates the lilong shikumen as a symbol of the city, the rent-only mode of business, the consumer group formed by tourists and Chinese and foreign white-collars of the $\mathrm{CBD}$ nearby, and the tourism and fashion resulting from the elaborate combination of commerce and culture. In fact, the creativity of Xintiandi lies in redevelopment instead of conservation. Since this area was not listed as an officially protected historic precinct at that time, other than preserving the general spatial arrangement and most of the exterior walls of the buildings, a thorough redesign to the structural framework, the flooring and inner space was applied, which gave the buildings a totally new appearance. The Xintiandi model, with its great commercial success, its trendy fusion effect with tradition and fashion, and its preservation of the urban historic texture, has been copied in other large cities as well. However, the success of Xintiandi in Shanghai has been hard to reproduce. Especially since the adoption of the Property Law, the conditions for the success of this type of conservation no longer exist. Thus, the Xintiandi model is still worth studying but probably irreproducible.

Second is the Tianzifang model. Tianzifang on Taikang Road is connected by small lanes over $100 \mathrm{~m}$ long and less than $3 \mathrm{~m}$ wide. It was originally called Zhichengfang, with art studios and workshops that started in the 1930s (after 1949, these were used as lilong factories). Compared to the surgical commercialisation of Xintiandi, the development of Tianzifang that started in 1998 has adopted a social participation approach for its revitalisation. This means a participating win-win model with the government making financial contributions to improve the infrastructure, some well-known artists moving in to revitalise art studios, residents living on upper floors and renting out the lower floors. For the past two decades, in the vigorous setting of longtangs (the lanes), it has witnessed a growing number of Chinese and foreign artists, business people and tourists which has made Tianzifang more and more famous, but driven up the costs at the same time. The result is a historical area and a lane-style creative park with the complete preservation of living and architectural styles of the lilong shikumen. Two advantageous conditions have 

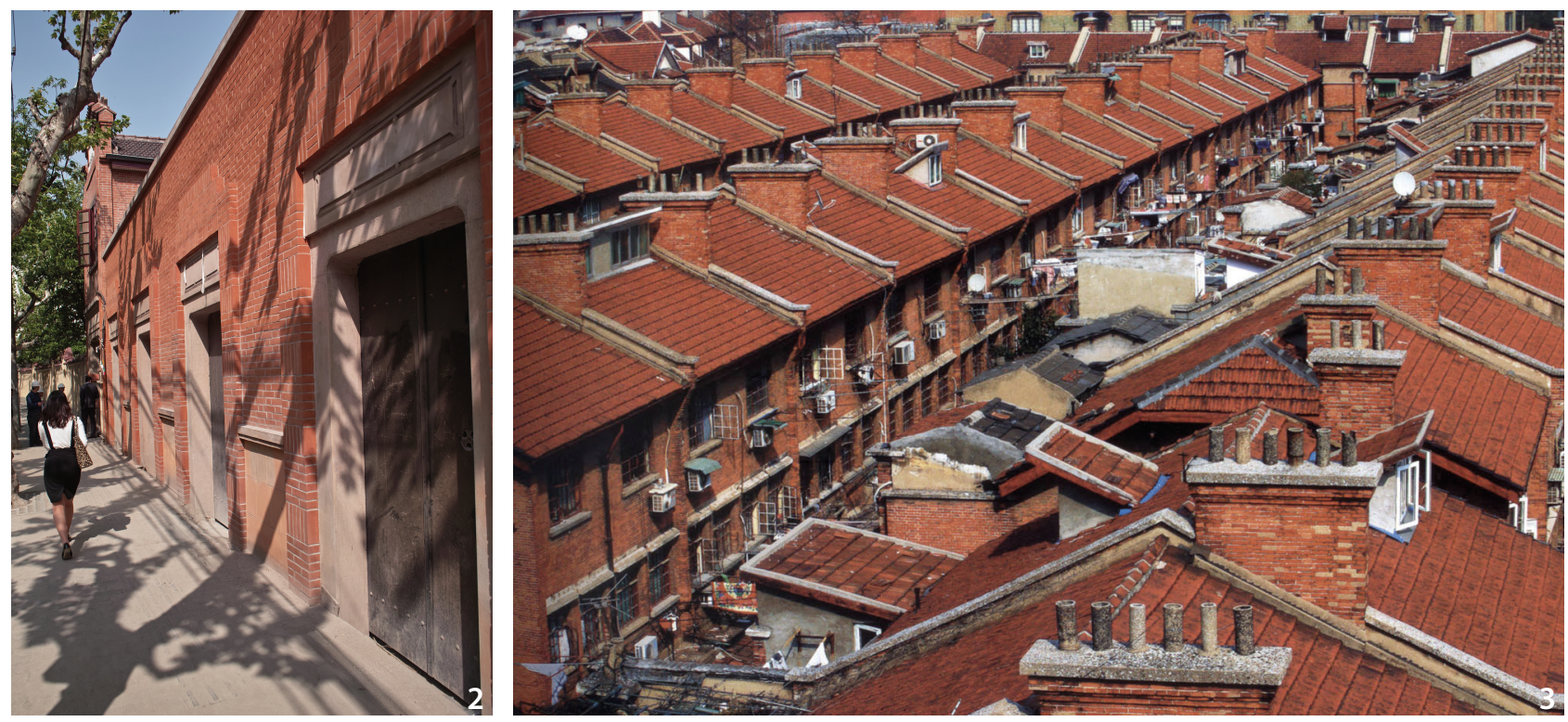

Figure 2 Architectural appearance of Jianyeli after partially reconstruction (Source: Chang Qing Studio).

Figure 3 Xiafeifang (Huaihaifang) in the former Luwan District, Shanghai (Source: Chen and Zheng 2006, 148).

enabled the success of Tianzifang, such as its unique 80 years long artistic tradition and the city's initiative to build creative longtangs.

The case of Tianzifang is actually a reversion of the government-developer-led large-scale demolition and high-end reconstruction model, attempting to create a support system among the tax collector (government), creators (artists), business owners, and house owners (residents), with every participant making its own contribution (essential infrastructure, artistic products, agency intermediation and the lease of spaces), and enjoying a win-win result, so as to ensure the conservation and continuation of the lanes' spatial characteristics and living style. Also it creates a new model of urban historical tourism and lanestyle creative industry. This model is nearly flat in structure, with no clear upward or downward direction. The four stakeholders involved no longer compete or bargain to each other, but share common interests. Besides, there is no involvement of developers. Though we can't say it will be impossible to reproduce the Tianzifang model, the question is how many lilong shikumen residential areas with the necessary historical resources are left for this development model?

The third is the Jianyeli model. Built in the 1930s, Jianyeli locates within the Hengshan Road Historic Area. It is a typical lilong shikumen residential quarter, having an area of around 1.79 ha and 260 shikumen houses. The main developing body is the government together with Chinese and foreign developers. In this project, $40 \%$ of the houses were restored and kept their original residential function, while $60 \%$ were demolished and 'reconstructed' to become an apartment-style hotel (Figure 2). Whether this mixed model of demolition and conservation will be successful or not is yet to be determined by careful study, but at present both the quality of restoration and the results of the 'reconstructed' sections have not received an extensive recognition from the professionals. And it is even harder to safeguard and interpret the authority and the effectiveness of conservation laws. The truth is, other than the second and third model, for the large amount of the lilong shikumen under the protection of relevant laws and regulations with low-standard living conditions, there is no better way so far to revitalise under the premise of conservation. Just like the antinomy where 'you can't have your cake and eat it', a choice is required to resolve this impasse, meaning that the policies on urban redevelopment have to be revamped thoroughly and more research on conservation and regeneration need to be done.

The fourth model is 'cultural relic conservation', which is applied to those lilong shikumen houses listed by the legal authorities in the framework of relevant laws on the protection of cultural relics, such as Yuyangli, which is designated as a 'Major Historical and Cultural Site Protected at the National Level', and Bugaoli and Shangxianfang, which are designated as 'Historical and Cultural Sites Protected at the Municipal Level. These cases are generally restored in strict accordance with cultural heritage conservation requirements, and attempts have been made to improve the water supply and sanitation facilities through new technologies and methods. Judging from the actual 


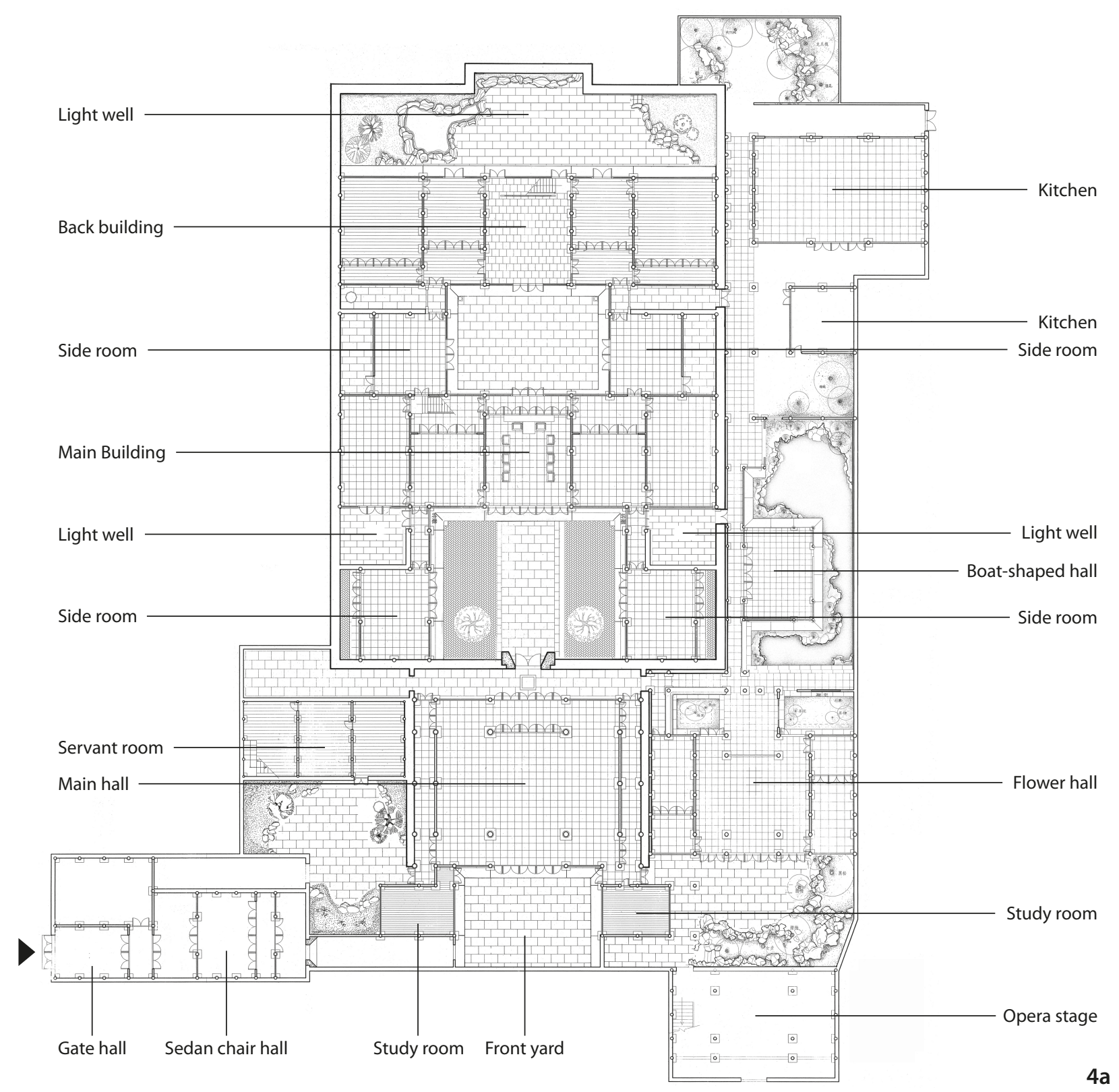

Figure 4a Ground floor plan of Shuyin Mansion (Source: Measured Drawings by the Department of Architecture, Tongji University).

result, these improvements have only satisfied minimal living standards, in order to achieve the requirements for privacy and equality. Also during this process, it is inevitable to reduce the architectural features and lower the quality of parts of the original historic space. For example, an original washroom for one house might be converted into a multi-household use washroom with small individual stalls, for this is a daily necessity for which there is no alternate choice. The largest financial support for this model comes from the government, the relic protection agencies give a medium support, and the residents pay the small part. Whether this improvement-based urban redevelopment model which involves the resident participation can be applied extensively to the large lilong shikumen areas protected under local regulations, is a major subject which needs to be explored with specialised studies determining if it might be the future direction (Figure 3).

Based on the introduction of the above four models, it is clear that the existence of those lilong shikumen which are not officially protected depends solely on the policy and the market; those protected under the cultural relic protections laws can generally be ensured a 'complete preservation'; those under the protection of local laws and regulations are in the dilemma of uncertainty between conservation and redevelopment; and those defined as 'reserved' under the conservation plans are in the most embarrassing situation: 


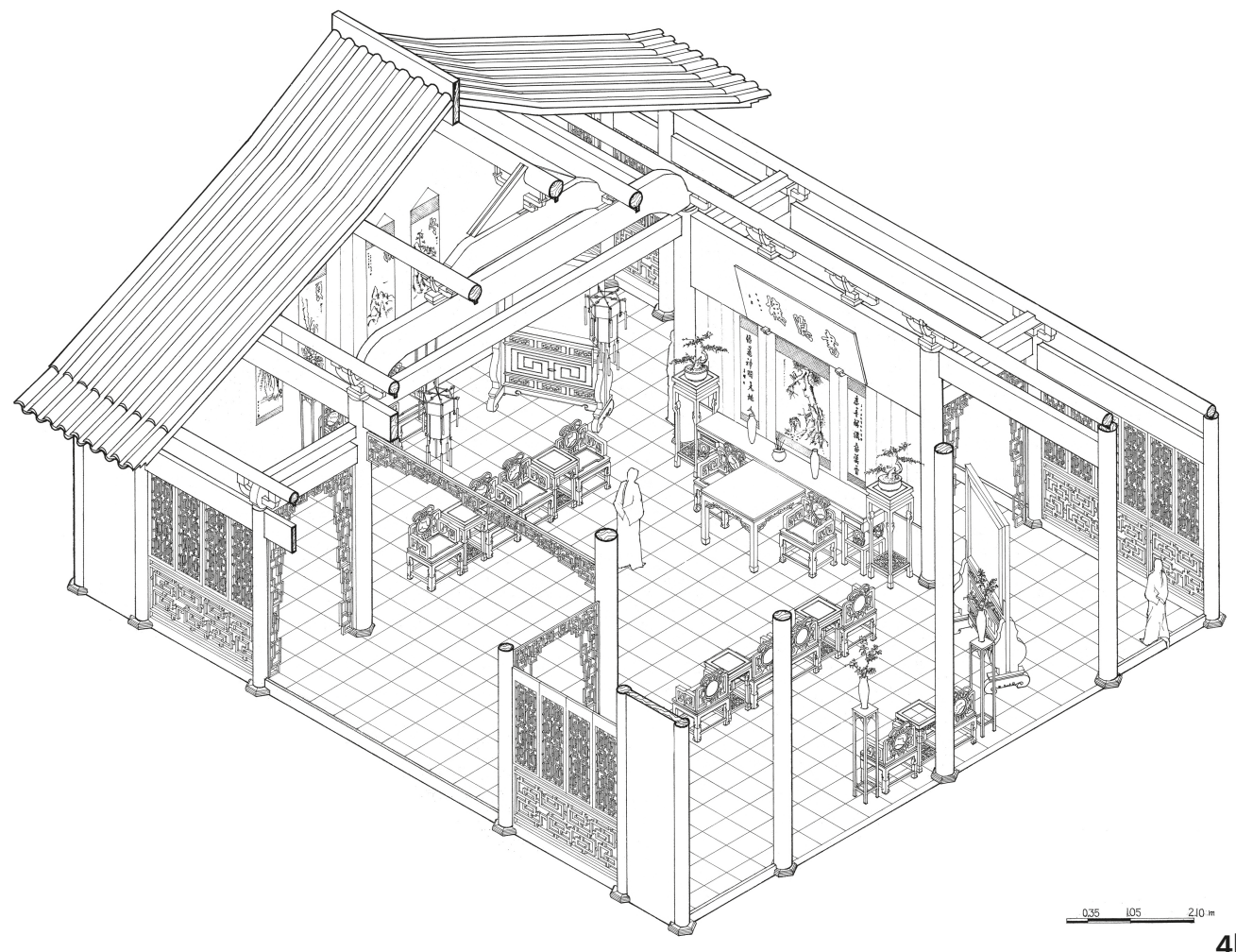

Figure $4 \mathrm{~b}$ Axonometric drawing of the main hall of Shuyin Mansion (Source: Measured Drawings by the Department of Architecture, Tongji University). they are either deemed to be 'not of big value', or considered as obstacles to urban redevelopment, which contradicts the original intentions to conserve them as a whole.

\section{The Suzhou-Style Garden Residence in Laochengxiang Historic Area}

The city of Shanghai has a history of over 700 years. But after modernisation during the last one and half century, and especially after the radical urban redevelopment undergone through the past two decades, there are only a few remains left to prove the city's ancient identity. As the epitome of ancient Shanghai, Laochengxiang has lost its former glory, except for the Yuyuan Garden and City God Temple area. Most historical sectors have only kept some structures and textures of the old city, whereas most historical buildings of this area have been demolished and redeveloped. So it is most lucky that Shuyin Mansion has been preserved in the process of the deterioration and radical transformation of the old city.

Shuyin Mansion is a private garden residence located at 77 Dongnan Tiandeng Lane in the Laochengxiang Historic Area of Shanghai. It was built at the end of the Qing Dynasty by the Fujian junk tycoon Guo Wanfeng's corporation on the site of the former Lu Residence. It is the only wholly preserved Suzhou-style garden residence in the Laochengxiang area of Shanghai. The origins of the residence site can be traced back to Rishe Garden built by the scholar Chen Suoyun under the Wanli Emperor's reign of the Ming Dynasty (1573-1620). Because it is a private property and the owner had a stable family business and kept a good family cultural tradition, though it is now in a critical condition after a hundred years' vicissitudes, its basic layout, the original buildings, the structures and the forms have been preserved without having been affected by demolition or unskilled repairs. Therefore, the heritage value of Guo's Shuyin Mansion mainly rests on its authenticity and its uniqueness.

This garden residence has an area of $3.4 \mathrm{mu}$ (around 0.56 acres), with a floor surface of around $2000 \mathrm{~m}^{2}$ (Figure 4a). The entrance is at the corner on Tiandeng Lane to its west (Zhusutang Street in the Qing Dynasty), then it leads from the west to the north, first the west-facing vestibule (destroyed), the sedan chair hall, then the narrow alley leading to the south-facing front yard which creates an open-up effect from narrowness. Northward, it is the main hall, the middle gateway on the wall (shikumen), and two courtyards: the front consists of a two-story main building and two side buildings, and a turntable building is in the back. The east part consists of the flower hall, the opera stage (destroyed) to the south, and the corridor against the eastern wall, a boat-shaped hall, the kitchens, and 


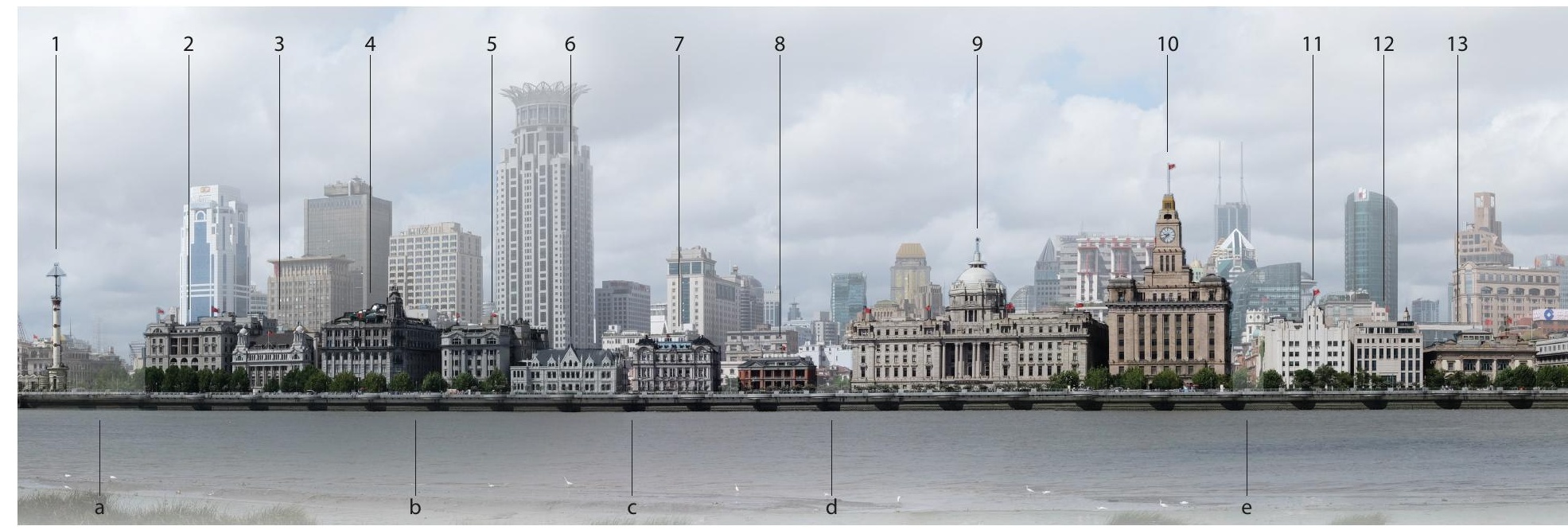

Figure 5 Panorama of the historic buildings along the Shanghai Bund (Source: Zhong Tang).

1. The former Gutzlaff Signal Tower built in 1907

2. The former McBain Building, 1913-1916 (No. 1 Zhongshan Dong Yi Road)

3. The former Shanghai Club, 1909-1910 (No. 2 Zhongshan Dong Yi Road)

4. The former Union Building, 1913-1916 (No. 3 Zhongshan Dong Yi Road)

5. The former Nishin Navigation Building, 1921-1925 (No. 5 Zhongshan Dong Yi Road)

6. The former Commercial Bank of China Building, 1921-1925 (No. 6 Zhongshan Dong Yi Road)

7. The former Great Northern Telegraph Building, 1906-1907 (No. 7 Zhongshan Dong Yi Road)

8. The China Merchants Steam Navigation Company Building built in 1901, (No. 9 Zhongshan Dong Yi Road)

narrow strip of rocks and pond to the north, creating a microcosm in the tiny landscape garden. This crowded arrangement reflects the scarcity of residential space in Laochengxiang at the end of the $19^{\text {th }}$ century. This Mansion follows the methods of the Xiangshanbang craftsmanship recorded in Yingzao Fayuan (Rules of Traditional Architecture), including the Suzhou-style halls (Figure $4 \mathrm{~b}$ ), buildings, guesthouses, and corridors, and various roofs, brackets and arches, carved columns, crescent beam, and carved wooden decorations. Carved windows, partitions, hanging fascia, and screens with a variety of images, the carved black bricks of the screen wall and door frame, the soft edged carvings on recliners, the tables, beds, and chairs, are especially valuable with their 'Shanghainese' touch from the end of the Qing Dynasty. These are the main reasons that this Mansion has got the attention both home and abroad. It is indeed a Shanghai's 'city treasure', and is definitely qualified to be granted as a state-level protected site.

From the perspective of urban historic space conservation, the current condition of Guo's Shuyin Mansion is also a typical case. As a 'Historical and Cultural Site
9. The former HSBC Building, 1921-1923 (No. 10-12 Zhongshan Dong Yi Road)

10. The Custom House, 1925-1927 (No. 13 Zhongshan Dong Yi Road)

11. The former China Bank of Communication Building, 1921-1923 (No. 14 Zhongshan Dong Yi Road)

12. Shanghai Public Service Centre (new building) ${ }^{1}$

13. The former Russo-Chinese Bank Building, 1921-1923 (No. 15 Zhongshan Dong Yi Road)

14. The former Bank of Taiwan, 1924-1927 (No. 16 Zhongshan Dong Yi Road)

15. The former North China Daily News Building, 1921-1924 (No. 17 Zhongshan Dong Yi Road)

16. The former Chartered Bank Building, 1922-1923 (No. 18 Zhongshan Dong Yi Road)

Protected at the Municipal Level', its conservation relies on the Shanghai Municipal Government, but the property ownership belongs to the Guo family. The deteriorated Mansion is in desperate need of repair, but it is very hard to balance the extent of responsibilities, rights and benefits of such repair investment. Obviously, there is the deep-rooted conflict between the public right of heritage conservation and the private right of property ownership, calling for a breakthrough to the bottlenecks of the conservation system and mechanism and reconsideration of the relevant laws and regulations in the future.

\section{The Bund Scenery}

If modern Shanghai's 'background' is the lilong shikumen houses that spread out horizontally, the lofty historic buildings are the most iconic 'figures' on it. This first and foremost 'figure' is no doubt the buildings on the Bund.

The English word 'Bund' originated from an Indian dialect, which means 'embankment' or 'quay' and afterwards has come to represent the waterfront promenade along Huangpu River flanked on the west side by a line of historic buildings. For nearly a century from the 1840 s to 


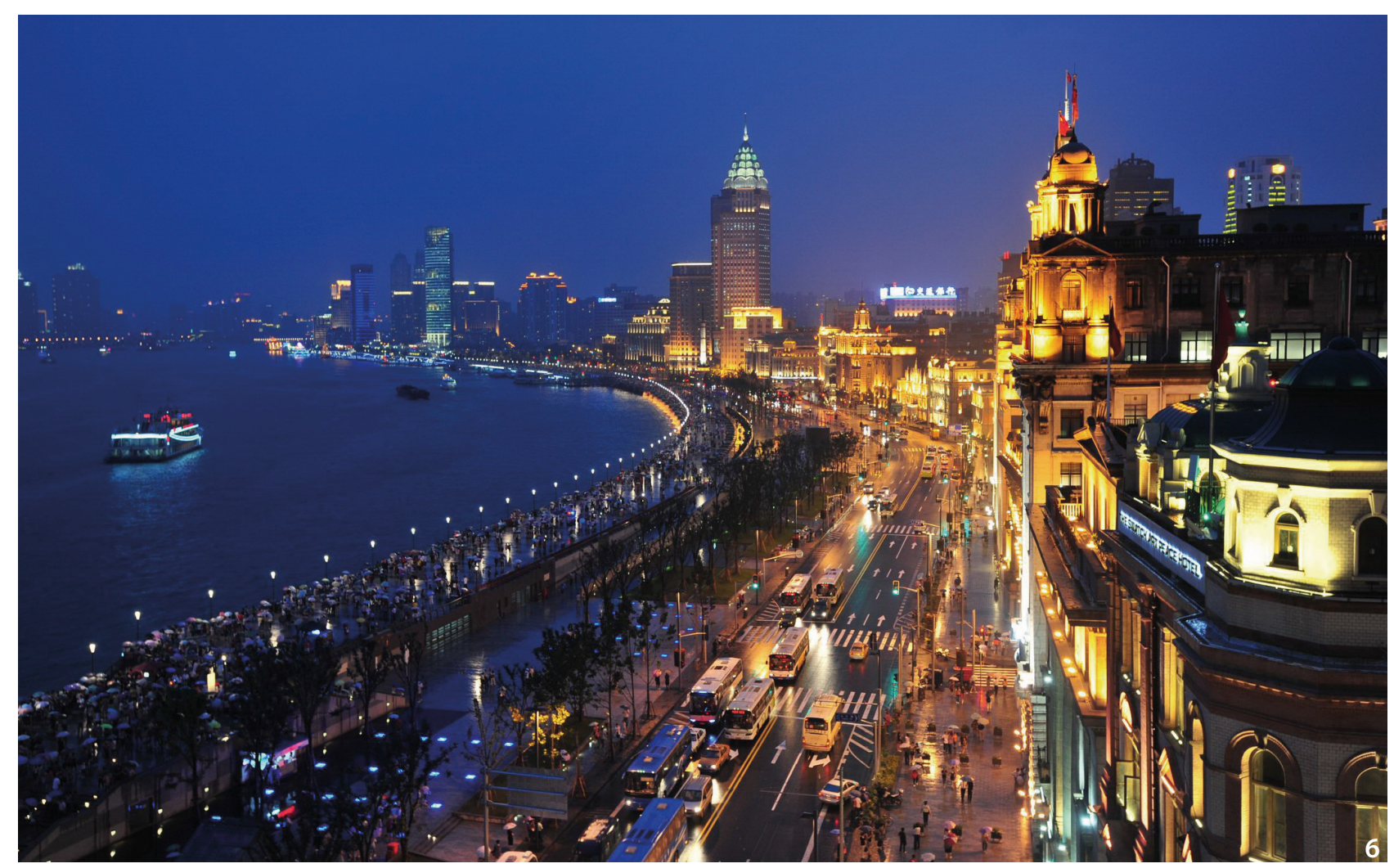

Figure 6 Night view of the Shanghai Bund scenic line (Source: Zhong Tang).

water-friendly floodwall, as a historic witness to Huangputan and its renowned Lovers' Wall, has already become an unforgettable part of Shanghai's urban memory. As an act of caution following the flood in 1981, the floodwall had been elevated to $6.9 \mathrm{~m}$ in the early 1990s according to once-in-a-millennium flood level, creating a box-structured sightseeing flood dam. The floodwall has expanded to the river, with its narrowest part at $6 \mathrm{~m}$ (Huangpu Park) and the widest part at $49 \mathrm{~m}$ (Shiliupu). Perched at the entrance of East Yan'an Road, the Gutzlaff Signal Tower had been moved $20 \mathrm{~m}$ eastward to make way for the floodwall project. The road surface on the Bund for motor vehicles doubled, becoming a major north-south traffic artery in the heart of the metropolis; many shops are also placed along the inside of the dam, resulting in the creation of a wide closed-off two-way street inconvenient for pedestrians, compared to the original one-way street with open view onto the water. However, in the end, a variety of municipal projects have greatly improved the waterfront space of the Bund with considerable efforts, such as optimising the dyke area, decreasing the roadway, widening the pedestrian sidewalks, and bringing underground motor vehicle traffic (Figure 6).

From the recent 20 years or more, the historic architectural waterfront on the Bund has undergone repeated conservations and transformations. The first conservation project was carried out in 1996 when $100,000 \mathrm{~m}^{2}$ of the exterior walls of the historic buildings were thoroughly cleaned. Since then, a series of interior and exterior renovations and functional adjustments have been carried out with the precondition of maintaining the architectural styles of the 'Modern Era. The timeline of these projects is: the former HSBC Building (now housing the Shanghai Pudong Development Bank), the former Union Building, the China Merchants Steam Navigation Company Building (Figure 7a-7g), the former Chartered Bank Building, the former Commercial Bank of China Building, the Bank of China Building, the former Sassoon House (now the North Building of the Fairmont Peace Hotel), the former Yokohama Specie Bank Building, and the former Jardine Matheson Building.

The goal of the interior renovations is to change functions of the buildings from mostly banks and offices to more cultural and leisure functions with the precondition of preserving the valuable historic space and interior decorative characteristics. For example, the strictest standards were adopted for the former HSBC Building and former Sassoon House, as the lobby and the mosaic murals in the octagonal dome of the former, and the Art Deco interiors of the public space of the latter are the most 

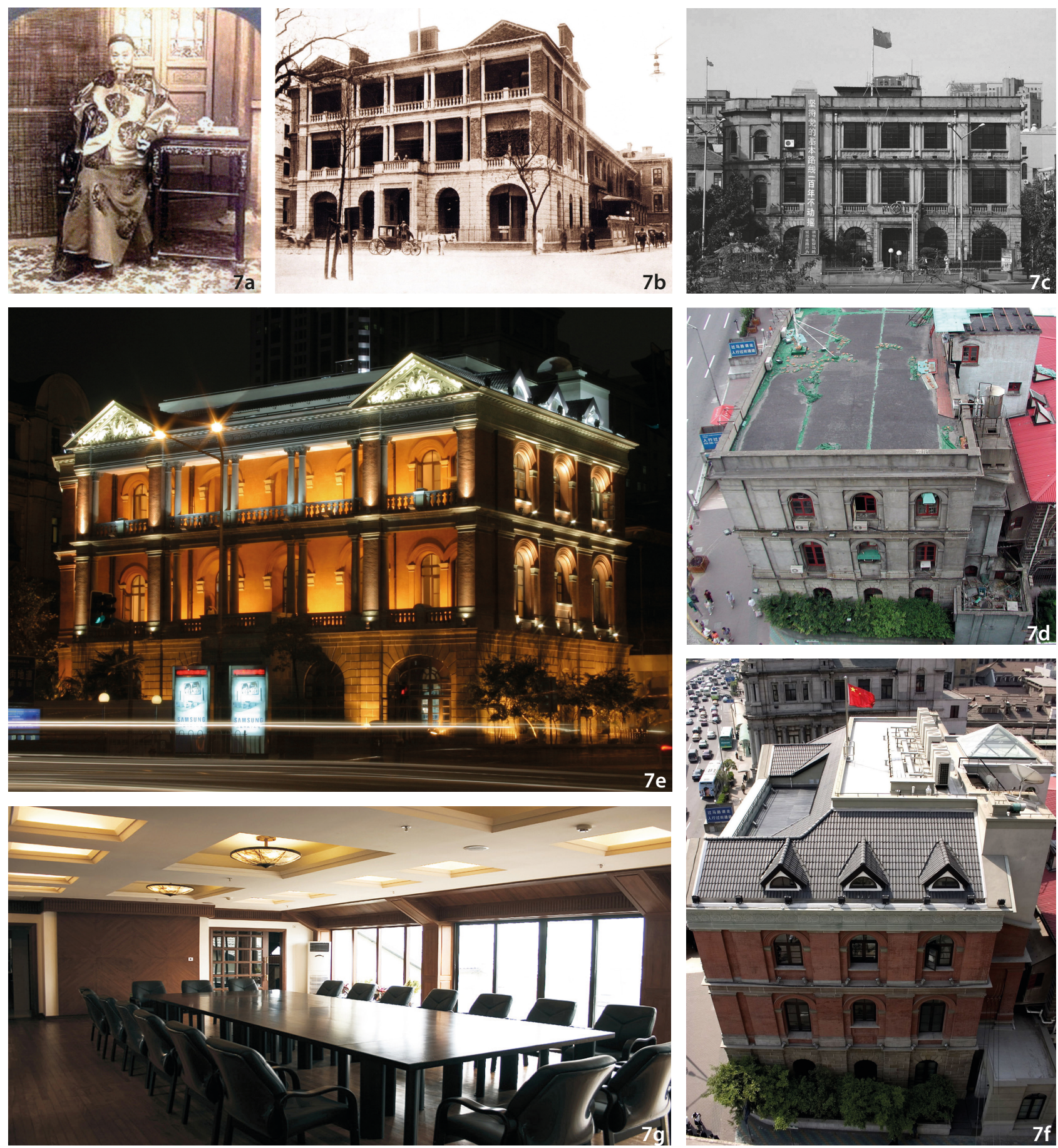

Figure 7a Portriat of Li Hongzhang (Source: Chang Qing Studio).

Figure 7b The China Merchants Steam Navigation Company Building in history (Source: Chang Qing Studio).

Figure 7c The China Merchants Steam Navigation Company Building before restoration (Source: Chang Qing Studio).

Figure 7d Roof of China Merchants Steam Navigation Company Building before restoration (Source: Chang Qing Studio).

Figure 7e The China Merchants Steam Navigation Company Building after restoration (Source: Chang Qing Studio).

Figure $7 f$ Roof of China Merchants Steam Navigation Company Building after restoration (Source: Chang Qing Studio).

Figure 7g The meeting room in the building (Source: Chang Qing Studio).

magnificent historic heritages (Figure 8a, Figure 8b).

The techniques used to protect the structural surface of the former Chartered Bank Building have achieved international standards, while the China Merchants Steam Navigation Company Building, being conserved by a professional team led by the author, is the only protected building on the Bund that was restored on the exterior and renovated on the interior. The regeneration of the former Union Building and Commercial Bank of China Building has seen an almost complete renewal of the original interior space 

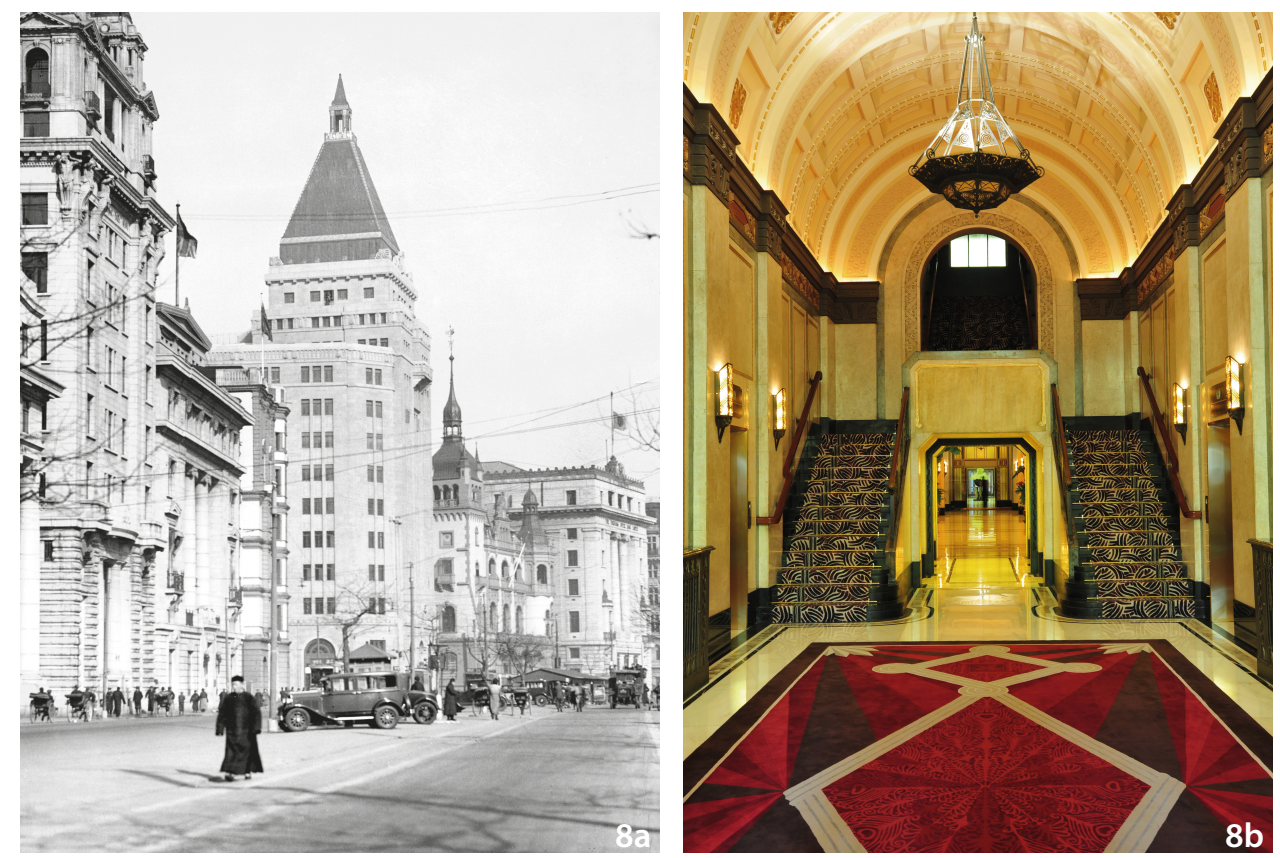

Figure 8a Sassoon House and the Shanghai German Club (right) in the early 1930s (Source: Zonghao Qian).

Figure $\mathbf{8 b}$ North Building of the Peace Hotel (the former Sassoon House) in 2010 after renovation

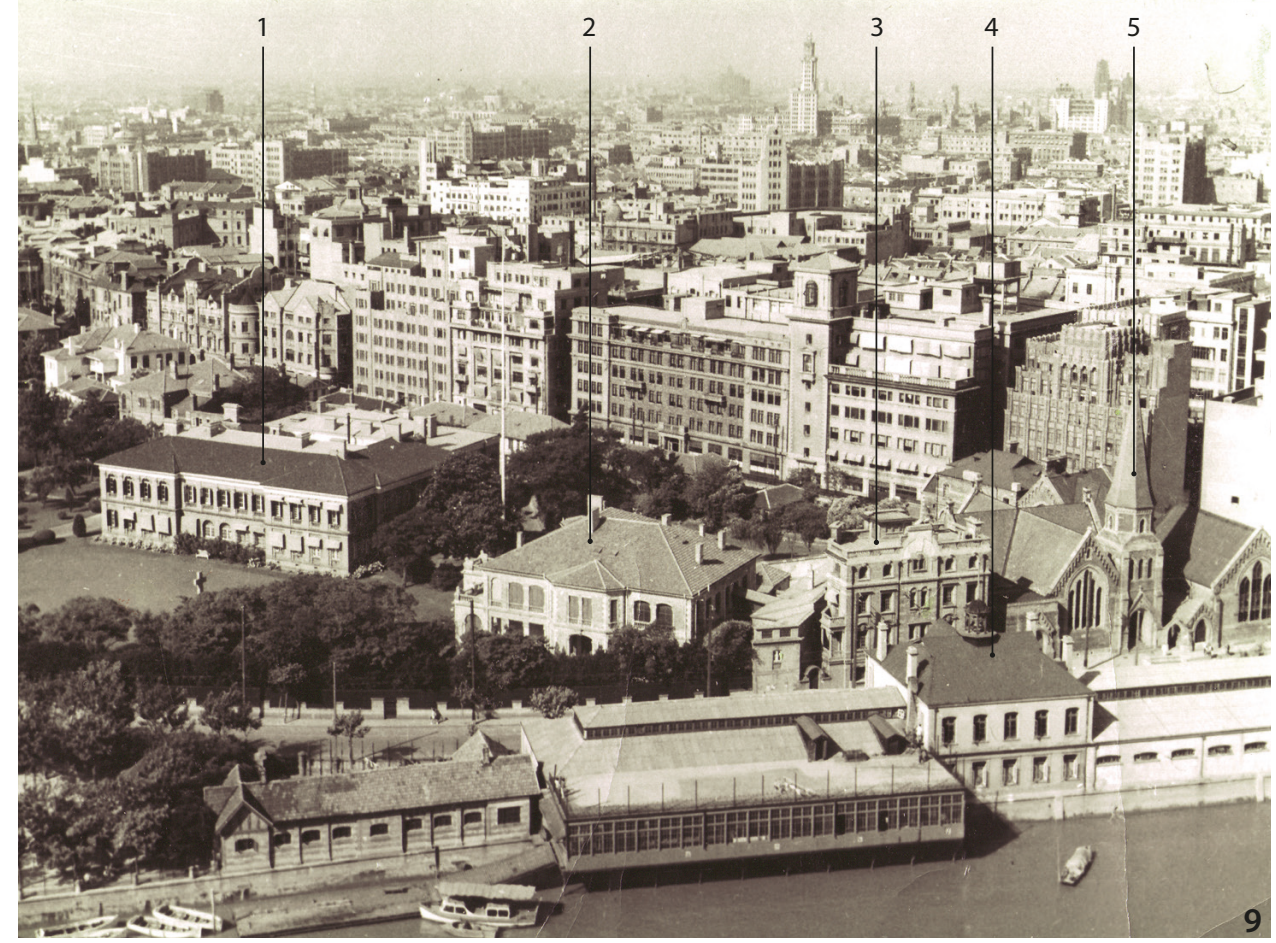

(Source: Zhong Tang).

Figure 9 The Waitanyuan Area in the early $20^{\text {th }}$ century (Source: Chang Qing Studio).

1. The British Consulate General

2. The Residence of the British Consulate General

3. The Priests Residence

4. The Shanghai Rowing Club

5. The Union Church

and structures. The restoration of the Waibaidu Bridge, which had been transported by ships to a factory for repair, has become a significant historic event for the city. On the whole, the reparation and restoration of the exteriors on the Bund's architectural ensemble, and the rehabilitation and renovation of the interiors, are meaningful explorations into the adaptive regeneration of historic space.

Nevertheless, the dignified exteriors of the Bund's architectural complex hide a 'hovelling' situation in the depth of these old buildings. The definite contrast between historic spaces is caused by various complicated social factors. Due to considerable complications in relocation and functional replacement, it's hard to find a cure for this 'stubborn illnesses' through regeneration under the preconditions of conservation, which is even more difficult than the conservation and regeneration of lilong shikumen. The only hope lies in the wisdom on the overall regulation and the strategies to balance opposing interests in the renovation of old area in the future. 
At the northern end of the Bund, the Waitanyuan situated at the junction between Huangpu River and Suzhou Creek is also an example in the exploration of the renovation of old urban districts. Waitanyuan literally means 'the origin of the Bund'. It is a new name in a new era, mainly referring to the urban precinct shaped from the middle and late $19^{\text {th }}$ century to the early $20^{\text {th }}$ century including the former British Consulate Building, the former Union Church, the former Priests' Residence, and the former Shanghai Rowing $\mathrm{Club}^{3}$ (Figure 9). This area ranges from Suzhou Creek in the north, Beijing Road in the south, the Bund to the east, and Middle Sichuan Road in the west, totalling an area of 17.6 ha that includes important historic neighbourhood of the 1930s clamped by Yuanmingyuan Road and Huqiu Road. This area contains a number of architectural works designed by renowned Chinese and foreign architects and architecture firms like L. E. Hudec, Poy Gum Lee and Palmer \& Turner. In 2001 the author was invited to propose the first round of conceptual planning for this area and since then has continued to follow its progress with interest (Chang 2003, 17). This is where the Suzhou Creek flows into the Huangpu River 'controlling the throat of the waterway to the east, and looking onto the riches of the west', and is also the most significant strategic hub in the era of water transportation. Thus, Waitanyuan has a special position in the modern history of Shanghai with its advantageous location, with a great potential for the future increase of property values. Since the beginning of the $21^{\text {st }}$ century the project has attracted many prominent brands from international investors and design institutions, which come and go all determined to remake the old commercial and cultural facilities into high-end business and leisure areas, meanwhile creating an open waterfront at the junction of the two rivers. Our conceptual planning began with historical research, tracing the geographical characteristics and their origins at the mouth of the rivers. The work also included field studies on the 14 protected buildings in this historic area, evaluating their status and values and estimating their potential for a multi-functional use. Research was conducted to assess the current environmental conditions of the Waitanyuan neighbourhood, including commerce, residence, traffic and green space to find a breakthrough for the conservation and regeneration of the entire area of the Bund. The historic scenery and evolution of the Waitanyuan waterfront on Suzhou Creek are therefore expressed through contrast and blending (Chang 2009b, 41-51) (Figure 10-13).

\section{Industrial Heritage}

By looking at the stages of the evolvement of an industrial city, the former top-tier industrial cities in China have either already become post-industrial cities or on their way, with Shanghai as a typical example. How to deal with the landscape of the industrial era and industrial architectural heritage ensembles thus becomes a vital problem. The process taken by Western industrial cities can shed some light on this. The first stage consisted on the complete demolition of old structures and their later redevelopment. Then, the second stage incorporated repair and reuse. Now, they are undergoing a stage of symbiosis between tourism and urban development. Today, Shanghai has surpassed the first stage, and started to experiment with the second and third stages.

For a decade or more, many creative parks have sprung up on South Suzhou Road, Moganshan Road, Bridge8 Area, Taikang Road, and Yangshupu area as a result of the transformation of the factories and warehouses along the banks of Huangpu River and Suzhou Creek. According to the historical characteristics of modern urban development, Shanghai has long been regarded as the cradle of Chinese industrial civilisation. Therefore, the urban heritage of Shanghai should no doubt include historical industrial spaces. Due to low rental prices and following the noble cause of heritage conservation, these deteriorated public spaces have been preserved and reused as trendy settings for arts, creative and design industry. In the transformation of Du Yuesheng's old granary in 1998, Taiwanese architect Deng Kunyan has recreated a Shanghai version of Scarpa's style and New York City's SoHo. He also successfully turned the heavy topic of industrial heritage conservation into an attractive and popular idea through a clever use of the mass media. To strengthen his concepts, he would even go to extremes to preserve historical information. For example, he went as far as insisting on the preservation of the original grimy brick surface of the original workers' shower room during the transformation of the auxiliary plant of the Yangshupu Power Station. However, the first group of people who were sensitive enough to start this trend were not strict preservationists. As artists and architects who are inherently after self-expression, they are more interested in the continuous creation of meaningful urban cultural matters than heritage conservation. In this case, the theme of their expression is the renewal of the remains of industrial space, which coincides with Shanghai's movement to preserve modern industrial heritage in the post-industrial era. The determination and efforts of this elite group has prevented the loss 

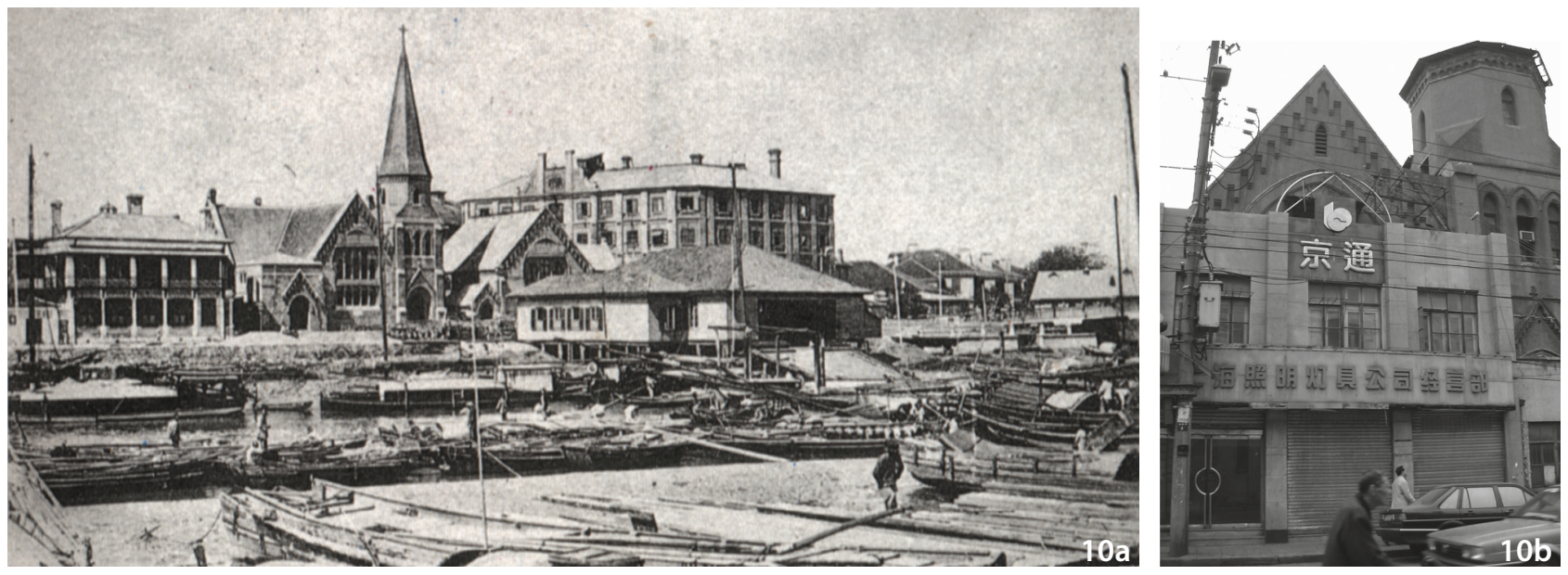

Figure 10a The Union Church before the construction of the Rowing Club (Source: H. Fluck, B. Fluck and Zhu 1993).

Figure 10b The Union Church in 2000 (Source: Chang Qing Studio).
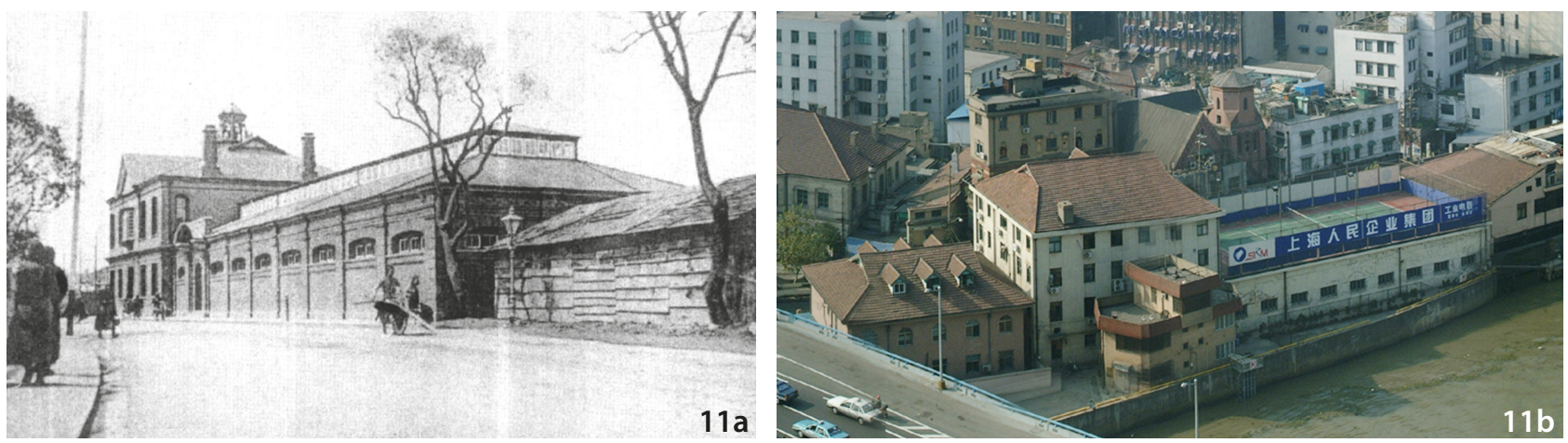

Figure 11 a The Shanghai Rowing Club in the early $20^{\text {th }}$ century (a) and 2001 (Source: http://blog.sina.com.cn/s/blog_bf6c87580101fd1f.html). Figure 11b The Shanghai Rowing Club in 2001 (Source: Chang Qing Studio).

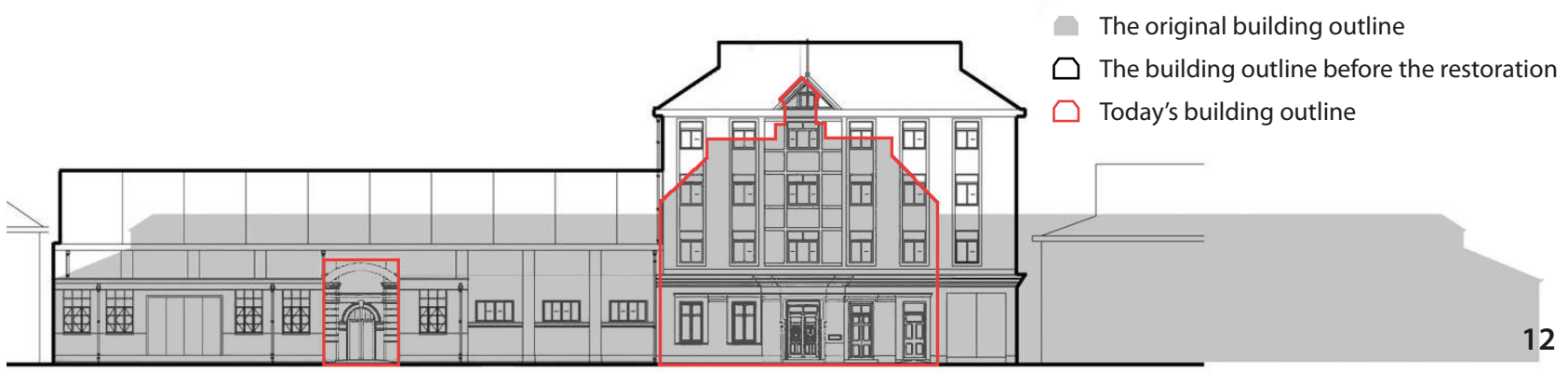

Figure 12 Changes of the building outline of the Shanghai Rowing Club (Source: Chang Qing Studio).
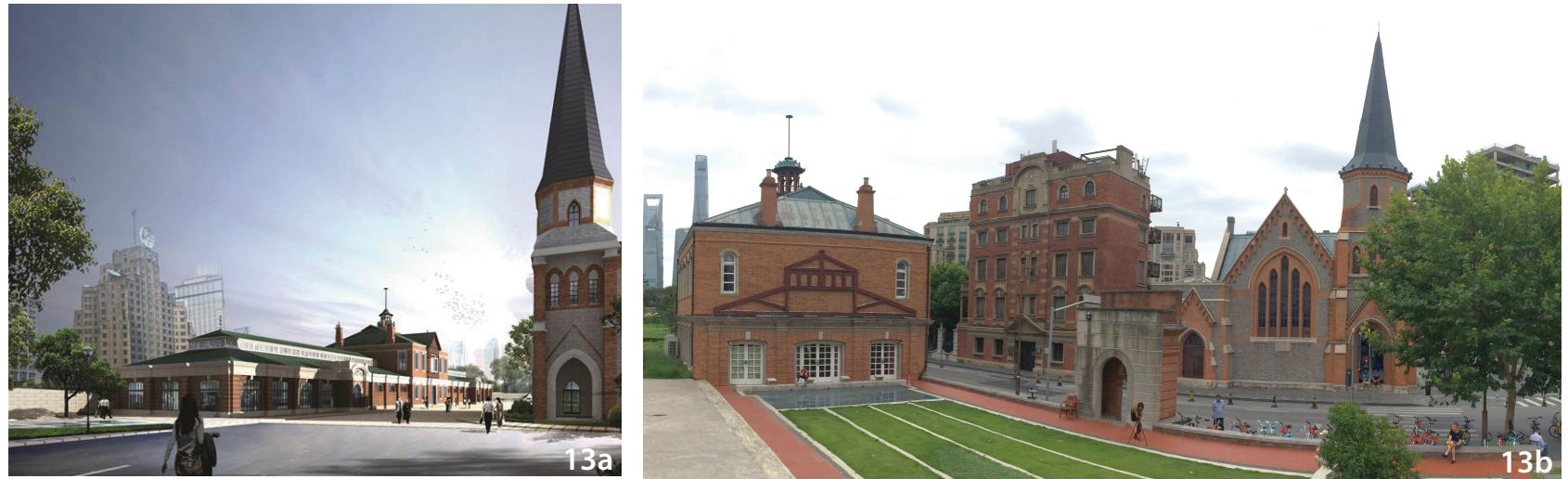

Figure 13a The restoration design proposal by Tongji University (Source: Chang Qing Studio).

Figure 13b The Shanghai Rowing Club, Priest Dormitory and the Union Church today (Source: Donghai Zhu). 

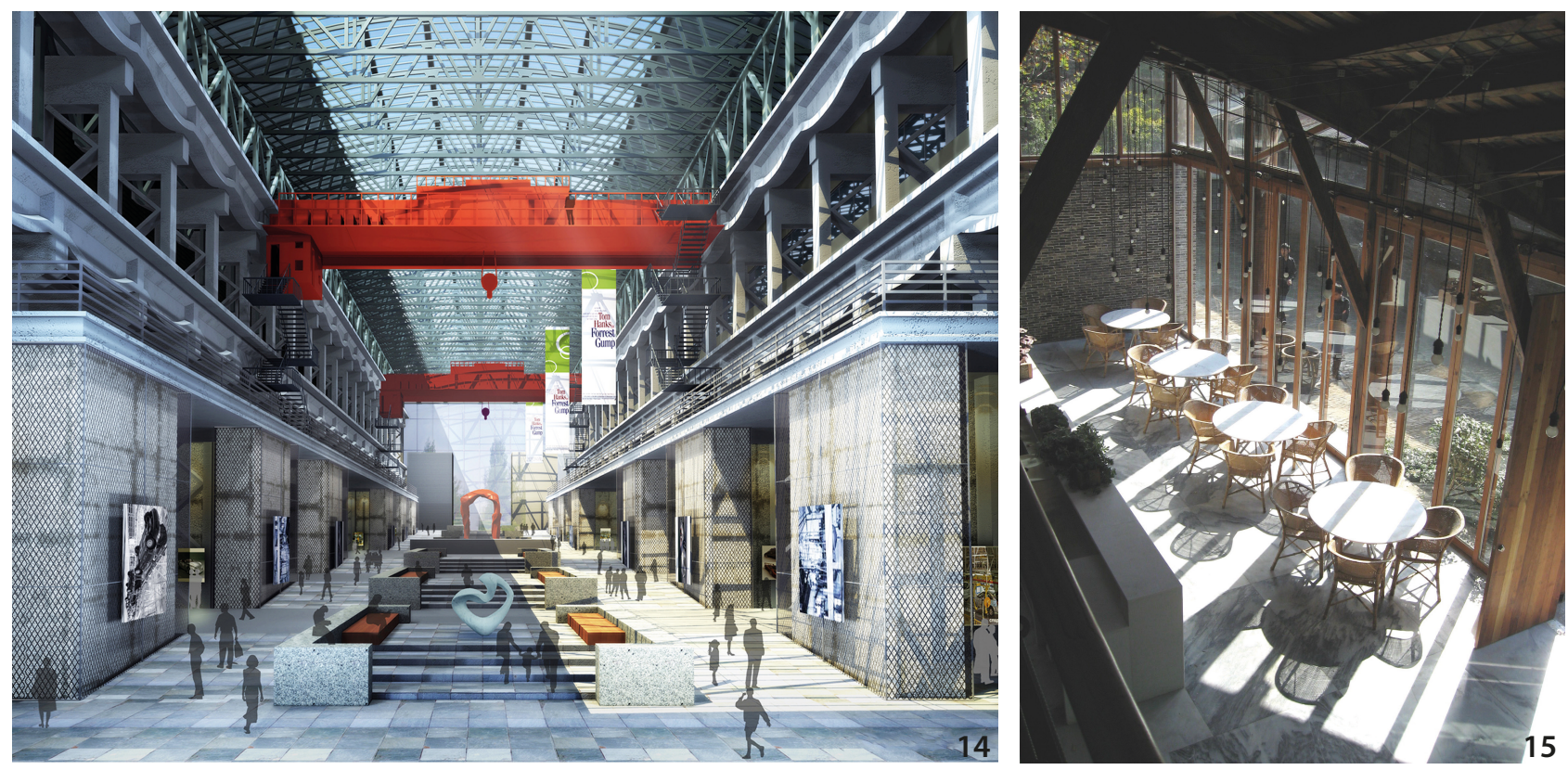

Figure 14 Renovation proposal for the Yangshupu Power Plant auxiliary equipment factory to be a museum (Source: Chang Qing Studio). Figure 15 The Yangshupu Power Plant auxiliary equipment after renovation (Source: Yan Zuo).

of some of the 'specimens' of Shanghai's historic industrial spaces. Whether it really fits into the creative industry itself has become secondary to the conservation and continuity of urban historic spaces.

Yangshupu, short for Yangshupu Harbour, is a $4.5 \mathrm{~km}$ long strip area along the Huangpu River from Jungong Road to Yangshupu Road. It is also informally called the 'East Bund'. The earliest public works in China can be found here, such as the water plant, the gas and heating plant, and the largest thermal power plant in the Far East at the time. There are also early machinery manufacturing industries built only a bit later than the Jiangnan Shipyard, such as the largest ship-repair factory, and soap factory, the earliest paper and cotton mills. Many noteworthy industrial buildings in the architectural history of China can also be found here, such as the earliest steel-reinforced-concrete factory building, the multi-story steel factory building; the tallest steel-framework factory building; the longest steel shipyard-style factory building, etc. Though most of these public works are still in use, as the industrial production declined in the new era, the empty factory buildings, the destitute shoreline, and the disordered landscape have all led to a deplorable image of Shanghai's eastern waterfront. A large quantity of the remaining industrial architecture and its land has been set aside and regarded as assets of the social security system, making their transformation and redevelopment extremely difficult. How to renew this old industrial strip under the premise of industrial heritage conservation is a not only a highly difficult task in practice, but also a high-risk investment. Between 2002 and 2004, we proposed a conceptual plan of spatial layout and development strategy for the four sections alongside Yangshupu, including the waterfront sightseeing area, 'Yangpu Forest' and industrial culture exhibition area, mixed urban area, and the knowledge-based residential area. In the proposal, the heritage architecture with great historical value should be preserved as a whole as the landmarks and memorials, methods of implantation and landscape restoration should be used to preserve and renew their interior and exterior environments so as to revive them in a sustainable way and be incorporated into the urban planning framework for the Yangpu District. As of now, some deserted industrial facilities such as the Shanghai No. 17 Cotton Mill and the Fisherman's Harbour in this old industrial strip have already been under commercial redevelopment. And the conservation and reuse of the industrial heritage are still under exploration (Figure 14, Figure 15).

\section{Metropolitan Historical Identity and Its Context}

\section{Historical Identity}

Shanghai's architecture has a unique urban historical context, without which it is not possible to understand the connection between its history and its current condition in the process of urban redevelopment. Traditionally, the cultural character of old Shanghai could be summarised in four keywords from the local Shanghai dialect, often 
with negative connotations: yangmaiban (comprador), laokele (classic), menkanjing (shrewd), and guanpaitou (to show-off). Whereas today, Shanghai has adopted four new phrases in Mandarin, as slogans summarising the new spirit of the city: hainabaichuan (diverse and inclusive), zhuiqiuzhuoyue (aspire for excellence), kaimingruizhi (liberal and sagacious), and daqiqianhe (generous and humble), all of which convey positive meanings. Though the new phrases sound completely different from the old words, both are related unconsciously and together define Shanghai's identity. On the one hand, a city that challenges and defies old urban culture; and on the other hand, a city that traditionally has accepted Western aesthetics as being 'superior'. Due to a reductive understanding of modern history, this 'Western style' so appreciated in the 1920s and 1930s mainly referred to the most conservative version of traditional Western architecture. Its backlash in the 1990s meant a strong inclination for classical 'European Continental style'. Although other cities may have shared this same inclination, its origin was in Shanghai.

Looking back to China's semi-colonial period, even Shanghai's elite class which included quite a number of people like Madam Soong Mei-ling saw themselves as 'banana-people', that is, Westernised Chinese with yellow skin and white mind, but none of them truly became yangnu (literally slave of foreign people) as they all had a strong self-consciousness as a Chinese. Although Shanghai went through a period of humiliation under the oppression of foreign powers, it had never been subjected to full colonisation like Mumbai or Hong Kong. Chinese people who lived within the foreign concessions never lost their national identity and self-consciousness as Chinese. After analysing the urban mentality and values of old Shanghai during the 'Modern Era' in the 1920s and 1930s, some scholars attributed these to 'Chinese cosmopolitanism, which means catering to, and being receptive towards the urban values and aesthetic appreciations brought about by Western modernity through industrialism and commercialism. This is the core value of the so-called Shanghai culture. As such, everything in old Shanghai, from the shape of a piece of cake, to the design of a pair of leather shoes or the form of a building conformed to these values. This became the measure of Shanghai's urban cultural status. This is why outsiders are seen as 'provincial', and affairs from outside of Shanghai are seen as 'foolish'. Even though 'cosmopolitanism' in its real sense goes beyond competition and means a 'universal value' that transcends nationality and race, and still a utopian concept embodying the ideals of human beings, Shanghai's
'Chinese cosmopolitanism' was actually a local concept. Taking the local people's attitude towards the Western architecture as an example, it evolved from contempt and curiosity gradually to appreciation and imitation, then to selection and incorporation, slowly acculturating these foreign styles as their own aesthetic values in the appreciation of architecture (Chang 2005, 2). This was opposite to the anti-imperialism and pro-nationalism advocated by the then government of the Republic of China, thus the revival of classical Chinese-style architecture (zhongguo guyou shi) had never become a mainstream in Shanghai. However, in light of this, Joseph Levenson argues that 'The very cosmopolitanism of some Shanghai Chinese, looking out from China, seemed a provincial variant, at the end of the line, to men who were looking in. The coin wavers, one side with the face of sophistication, the other with the face of questing, diffident innocence.' He further criticises that they seemed unable to 'assimilate the play[s] into Chinese needs and experiences' (Levenson 1971, 41). This implies that the Chinese community in old Shanghai, lacking a solid foundation in modernity, could only accept modern Western civilisation in appearance. As a result of the limitations of local cultures, it is difficult to completely internalise cosmopolitanism according to the Western standards. This disposition to acquiring identity through a shallow pursuit of Western civilisation has left a deep mark on the urban spirit of Shanghai.

\section{The Reverse 'Exoticism'}

Since the Reform and Opening-up in the late 1970s, Shanghai has prospered in many different fields after a long period of stagnation and isolation, due to overcome the insufficiency of the mainstream culture, and the anxiousness to make up for the lack of values and identity. Shanghai's 'collective unconsciousness' to embrace the Western culture emerged suddenly, superficial in its appearance, insufficient and inappropriate in its presentation. This led to a period of 'laokele' (old class) dreams and the nouveau riche's reverse 'exoticism' (originally referring to the fantasies and imitations on Chinese architecture and gardens in the European pre-Romantic period of the $18^{\text {th }}$ century.) This distorted awakening of the past 'Chinese cosmopolitanism' coincided with today's radical trends of globalisation, and has a full expression in architecture. For example, it seems fit to call Shanghai 'Paris of the East' based on its urban landscape. However, to believe that enjoying a cup of overpriced coffee in Xintiandi feels the same as in Paris seems pretentious. A European-style street in one district aimed to recreate La Rive Gauche in 


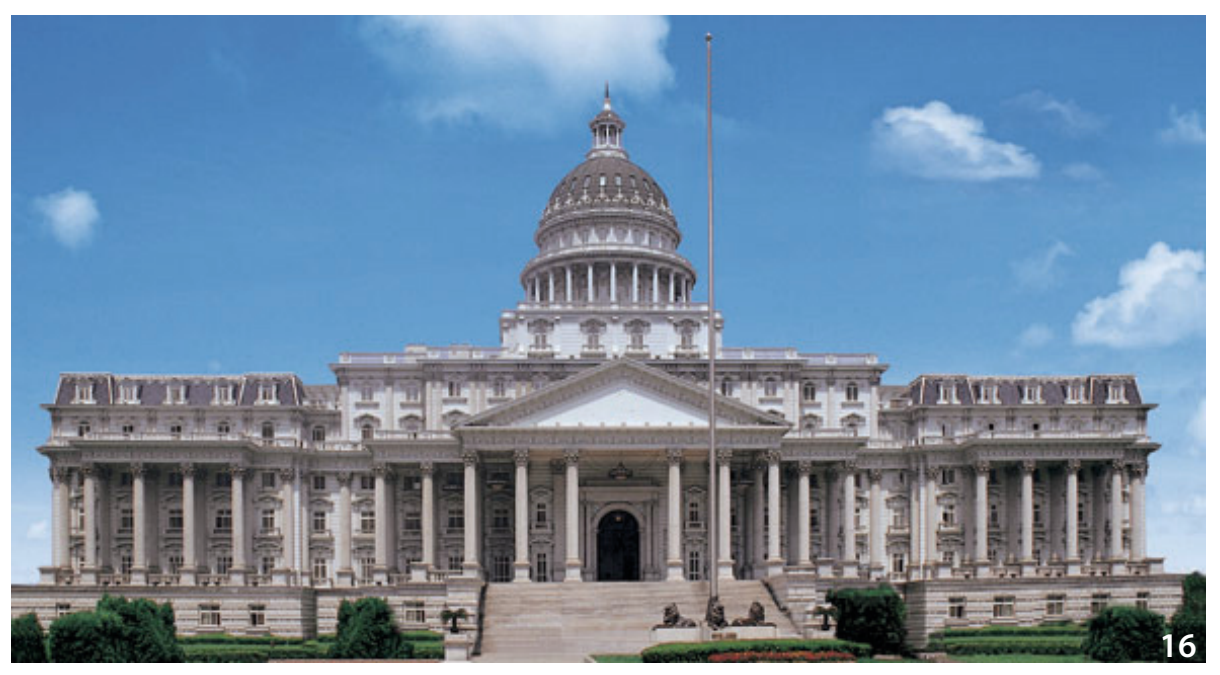

Figure 16 The Court House of Minhang District in Shanghai imitating the United States Capitol (Source: imedia. eastday.com.jpg).

Shanghai. The already renamed 'one city nine towns' concept, had used the excuse of countering 'boring uniformity' to recall old Western styles (Xue 2006, 105). Not only the European/American historic architectural styles were replicated, even their lifestyles were to be replicated. For example, one district was assigned the American style, so it planned to import American football as its community activity. The 'Thames Town' in Songjiang District was desolated until dozens of Western style wedding photo studios sprang up. The court house in one district built at the turn of the $21^{\text {st }}$ century actually copied the neoclassical United States Capitol entirely (Figure 16).

In order to emphasise the name 'Rockefeller', a 1.8 ha piece of development within the Waitanyuan area has been renamed as Rockbund. Even the roof of the twin towers at a well-known university campus has been topped with a couple of blue French Mansard roofs to show its 'rich culture'. There are innumerable examples like these. A vague 'European Continental style' has been popular in Shanghai's real estate market for quite a long time. Buildings with Western names and designs as a taste upgrading measure became a hot sale. It is incredible that with the old cloak of 'Chinese cosmopolitanism', it is possible to join the new gala of globalisation. This reverse 'exoticism' of course has something to do with the city's memory of it historical context. In reality, even today, being 'Western style' and 'aristocratic' are still real estate developers' big selling points. It is understandable that the nouveau riche has this preference, but it is still hard to understand why so many highly educated ordinary consumers have shown the same acceptance?

It is necessary to analyse the above phenomenon in detail. One reason is about cultural inferiority. Old foreign names and foreign outlooks seem more 'respectable', and suit the pursuit of social identity by many elites. Affected by this, ordinary people also regard everything that is foreign-related to be a measurement for social identity and status. This mentality is exactly the same as that of the old times. It shows that the perception of modernity and value judgment of the Chinese society is still lagging behind, which can be seen in the spiritual poverty and a thirst for empty extravagance. The other reason is the difference due to visual effect. The outlooks of many modern building of low or mediocre quality often deteriorates after a short period of use, not as lasting as those of Western classical style. As the pretentious classical ones look worthier than the deteriorated modern ones, so it is quite natural for the buildings with Western classical style to tag a higher price. But to the Westerners, some see this ridicule as a symptom of cultural inferiority of Chinese society, some are puzzled, despising the way Western architectural tradition has been distorted, because the majority of the so-called 'European classical styles' have been misinterpreted. From my perspective, to create architectural styles characterised by 'glocalisation' should be the mainstream of architecture in the course of urbanisation. In face of the unstoppable trend of global homogenisation, contemporary architecture should not only express modernity, but also exhibit features of adaptation to unique local environments and culture through the reflections on modernity. In other words, to preserve the diversification even as the trend of homogenisation continues. Though this is much more difficult than a simple replication of the West and the past, Shanghai's contemporary architecture should make some contributions in this field.

\section{Conversion of the Historical Context}

Besides the vigorous reverse 'exoticism', Shanghai's contemporary architecture has a different pursuit. The design 


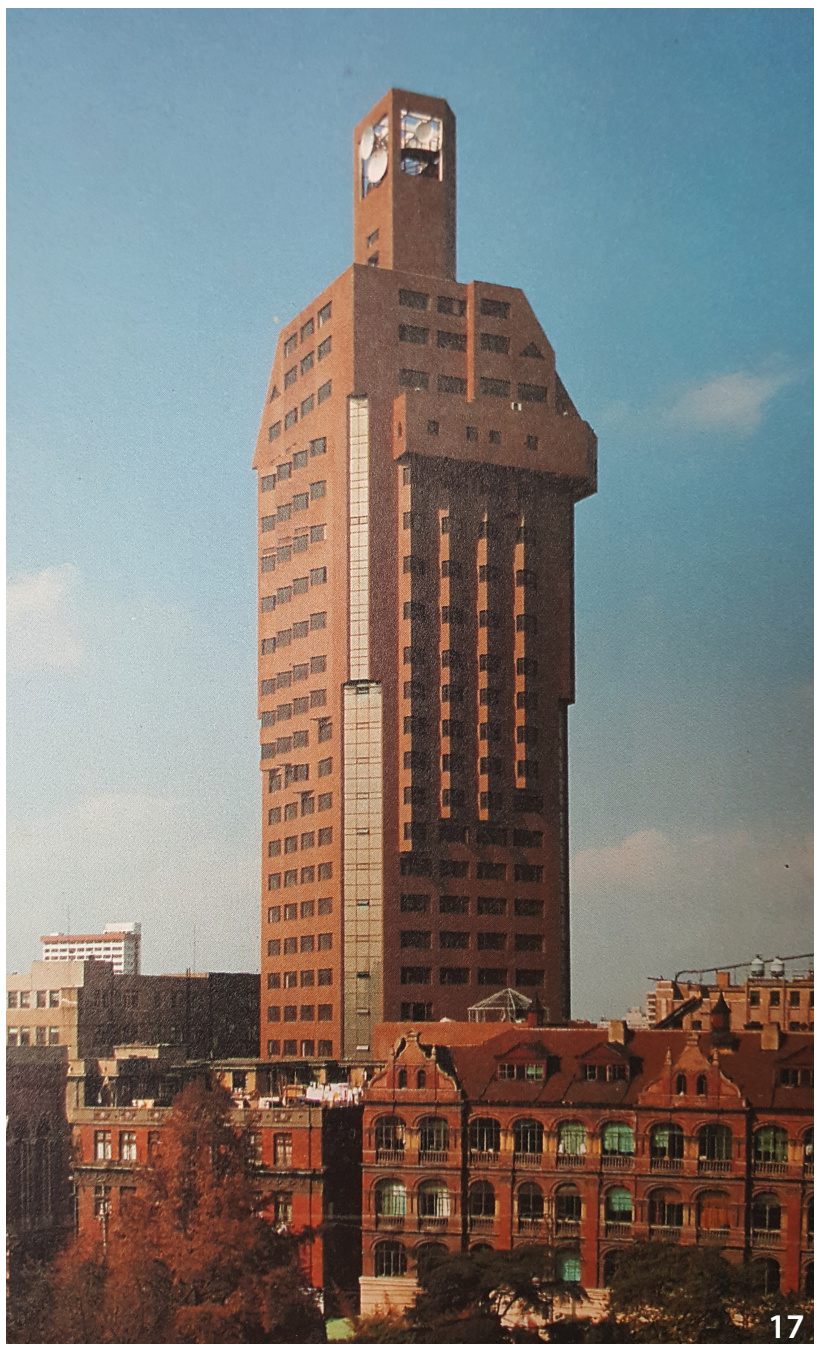

Figure 17 East China Electric Building along East Nanjing Road (Source: Xiao 1990, 7).

of the Square Pagoda Park in Songjiang District in the early 1980s, with its proud 'Theravada'-like gracefulness, has distinguished itself from the clamorous 'Mahasangha'like ordinary ones. Firstly, it has made full use of the 'three treasures', including the remains of the Square Pagoda from the Xingshengjiao Temple of the Northern Song Dynasty, the brick carvings and screen wall of the City God Temple of the Ming Dynasty, and the main hall of the Temple of the Queen of Heaven of the Qing Dynasty, and combined the conservation for local landmarks and relocated cultural relics. Secondly, by combining the traditional Chinese gardening's abstract aesthetic touch with the Western gardening's approach of displaying natural beauties, its naturally banked lake complement well with the park earth mounds and stone moats. Thirdly, hightechnique and folk expression are organically integrated in the architectural design. Therefore, the design of Square Pagoda Park incorporates smoothly the senses of history, modernity and locality, avoiding both a rigid compliance with the tradition and the blind pursuit of the current fashion. This mainly attributes to Tongji University's architectural tradition of 'striving for innovation' and the park's chief designer Mr Feng Jizhong's profound crosscultural capability.

Among the abundant architectural works designed by the mainstream Shanghai architects at the heart of the old Modern Shanghai area in the past two decades, Shanghai Library located on Middle Huanghai Road is a good example of carefully refined and simplified romantic neoclassical style. Shanghai Museum, in the shape of a stone Ding (an ancient food vessel often used as an indication of social status) located in the People's Square, has continuous geometric graphics on its façade to echo with its modern architectural designs. Meanwhile, there are two high-rises being worthy of special comparison. One is the Shanghai Telecom Building on the west side of People's Square. Its simple and graceful modern design, together with a skilful partitioning in some detailed parts, echoes with the historic space around while emphasising an orderly vertical façade. The other is the East China Electric Power Building on East Nanjing Road. It challenges the surrounding architectural environment with its emphasis on the changes of space by creating the effect of transition, distortion, and dynamical sense with the historical elements and its structural outline. In such prominent areas these new Shanghai architectures represent various discourses and aesthetic considerations on historic spaces (Figure 17).

By analysing the city's historical context and its contributing factors, it can be seen that at least from the end of the $19^{\text {th }}$ century, the urban and architectural form of Shanghai have always been following the trends of the West instead of adhering to that of the traditional Chinese styles (except for the architectural forms modelling after the traditional Chinese architecture under the directives of the 'Greater Shanghai Plan' by the government of the Republic of China in the 1930s). But the Laochengxiang Historic Area as an epitome of ancient Shanghai is undoubtedly an area of traditional Chinese style. The most prominent structure resulting from the conservational redevelopment of the surroundings of Yuyuan Garden and the City God Temple in the core of Laochengxiang during the mid-1980s, is the traditional-style architectural complex of the Yuyuan Garden Tourist Mart. It provides the scene of a busy folk-custom bazaar surrounded by densely-built large scale traditional Chinese-style commercial buildings with intertwining curving roofs. It 

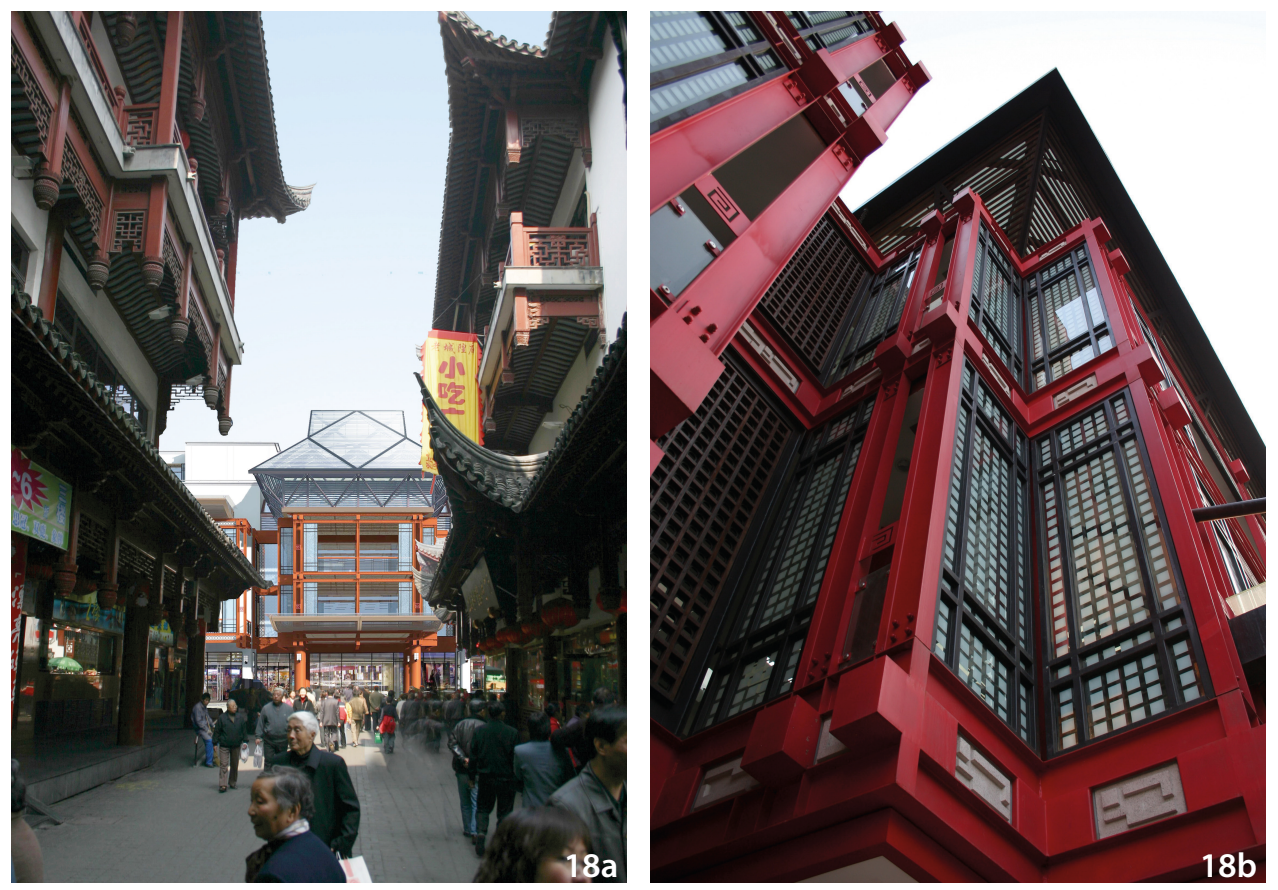

Figure 18a Jinyu Commercial Building, Middle Fangbang Road, Yuyuan Garden area (a dialogue with the traditional-style Yuyuan Mart) (Source: Chang Qing Studio).

Figure 18b Detail of Jinyu Commercial Building, Middle Fangbang Road, Yuyuan Garden area (Source: Zhong Tang).

becomes a favourite destination for Chinese and foreign tourists of all ages. The Tourist Mart even outshined the Yuyuan Garden, the real historical treasure which has a grand rockery of the Ming Dynasty and a wonderful Taihu Lake rock of the Song Dynasty. How to continue the redevelopment and keep the local features consistent around the edges of the Yuyuan Garden Tourist Mart are issues that have troubled this area for many years. In the design of the Jinyu Commercial Building along Middle Fangbang Road, an old street of the old city in the vicinity of Yuyuan Garden Mart, red modern steel-framed pavilions and terraces was proposed to be erected opposite the traditionalstyle architectural complex, the scenery of which could be summarised as 'old rhymes with new melodies, harmonious but distinctive' (Chang 2009b, 15, 203) (Figure 18a, Figure 18b).

A former prominent senior Shanghai architect, $\mathrm{Mr}$ Wang Dingzeng has indicated in the preface of a book that architecture 'should not simply follow fashionable trends, should not be new for the sake of being different, but should instead be rooted in the fundamental principles of architectural creativity, which are the zeitgeist and the local culture' (Zhang and Tang, 2003). Comparing his words with the slogan 'focusing on the evolution of history with a basis rooted in local soils' which was proposed by some experimental architects, it seems that they share similar basic architectural value which has more or less to do with the concept of 'glocalisation'. The only difference that lies between the different generations just refers to approaches and methods. The 'Qingpu Experiment' at the start of the $21^{\text {st }}$ century, with the slogan 'New Jiangnan Water Town', invited many experimental architects and firms from both home and abroad to use the popular architectural languages and phenomenological personal experiences to create a group of pioneering and distinctive experimental architectural landscapes in the County of Qingpu and the Town of Zhujiajiao. Is this 'fashion'? Is this 'zeitgeist'? At least the 'Qingpu Experiment' was an exploration into architectural design with certain standards.

In Shanghai there are also works by foreign architects that have received positive reviews because of the incorporation of traditional Chinese elements. For example, the design of the Shanghai Grand Theatre by Arte Charpentier Architectes was chosen by the Chinese judges because it evoked the image of fanyu, which is the Chinese inverse-curved roof, in their minds; the Shanghai Centre designed by John Portman and Associates has won praise by the use of Chinese elements and symmetrical composition; and the $420.5 \mathrm{~m}$ tall Jin Mao Tower designed by SOM is almost undisputed in its aesthetic value. It is not only due to its refinement in composition, material and form, but also to the Neo-Art Deco horizontal segmentation and the 33-story conical dome of the hotel at the top which are the metaphors of the two types of traditional Chinese pagodas, the multi-storied style and the multi-eave style. These examples show that foreign architects are also experimenting, whether intentionally or unintentionally, with glocalisation in architecture in a cosmopolitan city like Shanghai (Figure 19a, Figure 19b). 

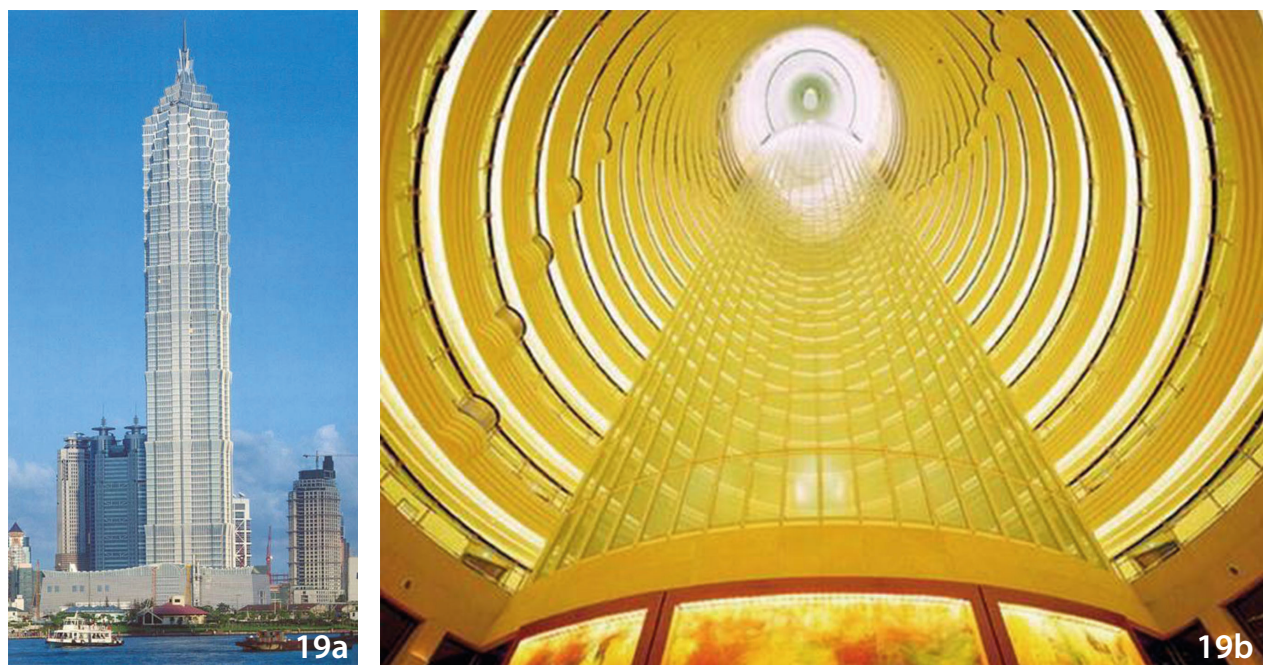

Figure 19a The Shanghai Jin Mao Tower, with its appearance bearing a unique charm of Chinese traditional pagoda (Source: Teaching materials of Architecture History Course of Tongji University). Figure $19 \mathrm{~b}$ The interior conical vault above the $55^{\text {th }}$ floor with sikhara flavour (Source: Teaching materials of Architecture History Course of Tongji University).

\section{Conclusion}

The trend for more mega-structures and high-rises in large metropolis is an unavoidable part of the urbanisation process. As a result, the large-scale urban redevelopment of the old areas has reduced the size and fragmented the historic spaces. However, historic spaces are the support of the spirit and cultural identity of the city, and are still the foundation of metropolitan vitality and diversity. Therefore, their authenticity and integrity should and could be conserved and kept active within the outlines of the gigantic structures of the expanded cityscape. Amidst the struggles of urban redevelopment, the regeneration of Shanghai's historic spaces has shown pros and cons. But undoubtedly it has proven itself a path worth practising and exploring. The unique historical context of urban culture has directly influenced the aesthetic appreciation and prevailing trends of Shanghai's architecture. In this sense, therefore, the purpose of this paper is to grasp the essential characteristics of the architecture in Shanghai and the evolving directions of 'glocalisation' by a thorough analysis from the macro-metropolitan context to the microarchitectural phenomena.

(Translated by Chen Chen, proofread by Zhengyue Qiao, Plácido González Martínez, and Yingchun Li)

\section{Notes}

1. The Shanghai Public Service Centre is a 'inlay project' along the Historic Bund scenic line, situating between the former Bank of Communications (No. 14 Zhongshan Dong Yi Road) and the former Russo-Chinese Bank (No. 15 Zhongshan Dong Yi Road). It was designed in 2004 by Shiling Zheng, the Academician of Chinese Academy of Sciences, and was completed and put into use in 2013. This six-storey buildingadopted typology as its primarily design methodappears a modern classical style with simple and humble touch, standing in harmony with the surrounding historic buildings and blending the old and new together perfectly.

2. The Peninsula Hotel (No. 32 Zhongshan Dong Yi Road) is a new Art Deco style building completed in 2009. It is located in the Waitanyuan area and extends to the waterfront space of the Bund on the site of the former Overseas Chinese Store and other old buildings built at the end of 1950s.

3. Located in No. 76 South Suzhou Road, the former Shanghai Rowing Club was built in 1905 and is one of the earliest extant sports buildings in China. Originally, it consisted of three parts, including the clubhouse in the centre, a boathouse in the west wing, and a natatorium in the east wing. In the 1990s, the boathouse was dismantled due to the construction of the gate bridge on Wusong Road and some other parts were rebuilt or expanded, making this historical building completely changed. In 2006, a professional team from Tongji University proposed a restoration and regeneration design for this building; and in 2009 they made an appeal to the Shanghai Municipal Government to prevent the building from the ongoing total demolition. In the end, a revised proposal was carried out by restoring the central clubhouse and tearing down the natatorium. The original swimming pool, in which a couple of World Champions in swimming had been trained after 1949, was partially conserved and divided into two parts, one covered by glass and the other by a turfed area decorated with 
patterns representing for the swim lanes. The entrance porch of the swimming pool was reconstructed as well. Besides, the roof truss of the natatorium was indicated on the side walls of the clubhouse, becoming a vital component of the historic landscape of the Waitanyuan area.

\section{References}

Chang, Qing. 2003. “Cong jianzhu wenhua kan shanghai chengshi jingshen-Huangpu jiangpan de jianzhu duihua." [Understanding the City Ethos of Shanghai through Architectural Culture: Dialog among the Buildings along the Huangpu River.] Architectural Journal 2003(12): 22-25.

Chang, Qing. 2003. Jianzhu yichan de shengcun celüe [A Conservative Strategy for Architectural Heritage]. Shanghai: Tongji University Press.

Chang, Qing, ed. 2005. Daduhui cong zheli kaishi-Nanjinglu waitan duan yanjiu [Origin of a Metropolis: A Study on the Bund Section of Nanjing Road in Shanghai]. Shanghai: Tongji University Press.

Chang, Qing. 2009a. “Jiugai zhong de Shanghai jianzhu jiqi dushi lishi yujing." [Shanghai Buildings Re-modeled in Old District and the Metropolitan Historical Discourse Context.] Architectural Journal 2009(10): 23-28.

Chang, Qing. 2009b. Lishi huanjing de zaisheng zhi dao [The Way to Historic Environment Rebirth through Design]. Beijing: China Architecture \& Building Press.

Chen, Haiwen, and Shiling Zheng. 2006. ChuanchengShanghai disipi youxiu lishi jianzhu [Inheritance-The Treasure of Heritage Architectures in Modern Shanghai]. Shanghai: Shanghai Culture Publishing House.

Fluck, Hans-R, Barbara Böke-Fluck, Jianhua Zhu. 1993. Historic Postcards of Shanghai. Shanghai: Tongji University Press.

Koolhaas, Rem. 1978. Delirious New York: A Retroactive Manifesto for Manhattan. New York: Oxford University Press.

Levenson, Joseph. R. 1971. Revolution and Cosmopolitanism: the Western Stage and the Chinese Stage. Los Angelos: University of California Press.

Shanghai Urban Construction Archive, ed. 2014. Shanghai shi lishi wenhua fengmao qu [Historic Areas in Shanghai]. Shanghai: Shanghai People Publishing House.

SUPAB (Shanghai Urban Planning Administration Bureau). 2007. Shanghai chengshi guihua guanli shijiankexue fazhanguan tonglingxia de chengshi guihua guanli shijian tansuo [Urban Planning Administration
Practices in Shanghai-An Exploration of Urban Planning Administration under the Scientific Concept of Development]. Beijing: China Architecture \& Building Press.

Xue, Qiuli. 2006. Quanqiuhua chongji-haiwai jianzhu sheji zai zhongguo [The Global Impact: Overseas Architectural Design in China]. Shanghai: Tongji University Press.

Zhang, Jiezheng, and Yuen Tang. 2003. Chuancheng fazhan tansuo [Inheritance, Development, Exploration]. Shanghai: Shanghai Scientific \& Technical Publishers.

Zheng, Shiling. 2002. "Shanghai chengshi kongjian de dangdai fazhan." [Contemporary Development of Urban Space Environment in Shanghai.] Architectural Journal 2002 (2): 15-20. 